\title{
THE INDUCED INNOVATION HYPOTHESIS AND ENERGY-SAVING TECHNOLOGICAL CHANGE
}

\author{
Richard G. Newell \\ Adam B. Jaffe \\ Robert N. Stavins
}

Working Paper 6437 
NBER WORKING PAPER SERIES

\title{
THE INDUCED INNOVATION HYPOTHESIS AND ENERGY-SAVING TECHNOLOGICAL CHANGE
}

\author{
Richard G. Newell \\ Adam B. Jaffe \\ Robert N. Stavins
}

\author{
Working Paper 6437 \\ http://www.nber.org/papers/w6437 \\ NATIONAL BUREAU OF ECONOMIC RESEARCH \\ 1050 Massachusetts Avenue \\ Cambridge, MA 02138 \\ March 1998
}

This paper is based on Newell's Ph.D. dissertation at Harvard University. We thank, without implicating, Robert Deacon, William Hogan, Raymond Kopp, Albert Nichols, William Pizer, and Martin Weitzman for useful comments. We also thank Suzanne Kim, Sandip Madhavareddy, and Karthik Muralidharan for excellent research assistance. The research was supported by U.S. Department of Energy award No. DE-FG02-95ERG2106, a Resources for the Future Joseph L. Fisher Dissertation Award, and a John F. Kennedy School of Government Joseph Crump Fellowship. Such support does not constitute an endorsement by those institutions or the National Bureau of Economic Research of the views expressed in this paper.

(C) 1998 by Richard G. Newell, Adam B. Jaffe and Robert N. Stavins. All rights reserved. Short sections of text, not to exceed two paragraphs, may be quoted without explicit permission provided that full credit, including (C) notice, is given to the source. 
The Induced Innovation Hypothesis

and Energy-Saving Technological Change

Richard G. Newell, Adam B. Jaffe

and Robert N. Stavins

NBER Working Paper No. 6437

March 1998

\begin{abstract}
$\underline{\text { ABSTRACT }}$
It follows from Hicks' induced innovation hypothesis that rising energy prices in the last two decades should have induced energy-saving innovation. We formulate the hypothesis concretely using a product-characteristics model of energy-using consumer durables, augmenting Hicks' hypothesis to allow for the possibility that government efficiency standards also induce innovation. Through estimation of characteristics transformation surfaces, we find that technological change reduced the total capital and operating costs of air conditioning by one-half and water heating by about one-fifth. Although the rate of overall innovation in these products appears to be independent of energy prices and regulations, the evidence suggests that the direction of innovation has been responsive to energy price changes. In particular, energy price increases induced innovation in a direction that lowered the capital cost tradeoffs inherent in producing more energy-efficient products. In addition, energy price changes induced changes in the subset of technically feasible models that were offered for sale. Our estimates indicate that about one-quarter to one-half of the improvements in mean energy-efficiency of the menu of new models for these products over the last two decades were associated with rising energy prices since 1973. We also find that this responsiveness to price changes increased substantially after product labeling requirements came into effect, and that minimum efficiency standards had a significant positive effect on average efficiency levels. Nonetheless, a sizeable portion of efficiency improvements in these technologies appears to have been autonomous.
\end{abstract}

Richard G. Newell

Resources for the Future

1616 P Street, NW

Washington, DC 20036

Robert N. Stavins

John F. Kennedy School of Government

Harvard University

79 JFK Street

Cambridge, MA 02138
Adam B. Jaffe

Department of Economics

Brandeis University

Waltham, MA 02254

and NBER

ajaffe@nber.org 


\title{
The INDUCED INNOVATION Hypothesis AND ENERgY-SAVING TeCHNOLOGICAL CHANGE
}

\author{
Richard G. Newell, Adam B. Jaffe, and Robert N. Stavins *
}

\section{INTRODUCTION}

There is currently much interest in the potential for public policies to reduce energy consumption because of concerns about global climate change linked with the combustion of fossil fuels. Basic economic theory suggests that if the price of energy relative to other goods rises, the energy intensity of the economy will fall as a result a series of behavioral changes: people would turn down their thermostats and drive slower; they would replace their furnaces and cars with more efficient models available on the market; and over the long run, the pace and direction of technological change would be affected, so that the menu of capital goods available for purchase would contain more energy-efficient choices.

This last conjecture - that increasing energy prices will lead to technological change that facilitates the commercialization of capital goods that are less energy-intensive in use — is a modern manifestation of the "induced innovation" hypothesis of Sir John Hicks: "a change in the relative prices of the factors of production is itself a spur to invention, and to invention of a particular kind - directed to economizing the use of a factor which has become relatively expensive." (1932, pp. 124-125).

\footnotetext{
Newell is a Fellow at Resources for the Future; Jaffe is an Associate Professor in the Department of Economics, Brandeis University, and a Research Associate at the National Bureau of Economic Research; and Stavins is a Professor of Public Policy at the John F. Kennedy School of Government, Harvard University, and a University Fellow at Resources for the Future. This paper is based on Newell's Ph.D. dissertation at Harvard University. We thank, without implicating, Robert Deacon, William Hogan, Raymond Kopp, Albert Nichols, William Pizer, and Martin Weitzman for useful comments. We also thank Suzanne Kim, Sandip Madhavareddy, and Karthik Muralidharan for excellent research assistance. The research was supported by U.S. Department of Energy award No. DE-FG02-95ERG2106, a Resources for the Future Joseph L. Fisher Dissertation Award, and a John F. Kennedy School of Government Joseph Crump Fellowship. Such support does not constitute an endorsement by those institutions of the views expressed in this paper.
} 
There is a considerable theoretical and empirical literature on the induced innovation hypothesis, often formulated as the principle that increases in real wages will induce labor-saving innovation, but that literature typically analyzes the inducement effect in the framework of an aggregate production function. ${ }^{1}$ Technological change, however, is inherently a microeconomic phenomenon. If the inducement mechanism operates with respect to energy, it does so largely by leading firms to introduce new models of cars, appliances, and industrial equipment that deliver greater services per unit of energy consumed. From this perspective, it seems natural to formulate the inducement hypothesis in terms of a product characteristics framework, summarizing the technological possibilities for the production of a good as a menu of feasible vectors. Each vector represents the characteristics of technically feasible models, including the resource cost of producing such models. Technological change is the introduction into the relevant menu of a vector that was previously not available. The inducement hypothesis implies that when energy prices rise, the characteristic "energy efficiency" of items on the capital goods menu should improve faster than it otherwise would.

In this paper, we formalize the inducement hypothesis in this framework and we test it empirically. We also generalize the Hicksian notion of inducement to investigate whether government regulations have affected energy-efficiency innovation. We find evidence that both energy prices and government regulations have affected the energy efficiency of the models of room air conditioners, central air conditioners, and gas water heaters available on the market over the last four decades, although there have also been substantial improvements in energy efficiency that do not appear to be induced by price changes or regulations.

\footnotetext{
${ }^{1}$ See Thirtle and Ruttan (1987) for a summary of this literature.
} 
In the following section of the paper, we describe technological change in terms of product characteristics, and develop the distinction between improvements in efficiency due to changes in technological possibilities, and improvements due to changes in the "substitution" of models along a given set of technological possibilities. In section III, we describe our data, and in section IV, we present empirical estimates of the rate and direction of technological change for the three products over the past several decades, and the extent to which these have been induced by prices and regulations. In section $\mathrm{V}$, we assess the overall importance of technological change and model substitution in generating changes in the composition of models actually offered along the frontier, and in section VI, we offer some concluding observations.

\section{Measuring InNovation In A Product Characteristics Framework}

\section{II.A. THE CHARACTERISTICS TRANSFORMATION SURFACE}

Theoretical analysis within the product characteristics framework has been discussed by numerous authors. ${ }^{2}$ Our interest is in empirical implementation, so we move quickly from the abstract and general to the concrete and specific.

Consider a firm that uses $m$ possible inputs $\left(x_{1}, \ldots, x_{m}\right)$ to produce one or more models of a product that can be described in terms of $n$ characteristics $\left(y_{1}, \ldots, y_{n}\right)$, where the characteristics are measured in physical units (for example, cooling capacity and energy use in a room air conditioner). For any product model, the firm faces tradeoffs in the bundle of characteristics it can produce from the input set. Combining these characteristic outputs and resource inputs into a vector of dimension $m+n\left(z_{1}, \ldots, z_{m+n}\right)$, these tradeoffs can be represented by a transformation surface:

\footnotetext{
${ }^{2}$ See Rosen (1974), Triplett (1985, 1987), Trajtenberg (1990), and Berry, Levinsohn, and Pakes (1995).
} 


$$
\Psi\left(z_{1}, \ldots, z_{m+n}\right)=0
$$

The transformation surface describes the various bundles of characteristics, or product models, that can be produced with existing technology from various levels of resource inputs. For example, energy-efficient air conditioners require less electricity to produce cooling services, but their construction requires more cooling coils, a larger condenser, a larger evaporator, and perhaps a "power-saver" switch to cycle the fan on and off. Likewise, high-efficiency gas water heaters have four times the insulation of standard models, greater flue baffling, and special pilot lights. There are other cases where characteristics are complements, rather than substitutes. The use of plastics in cars, for example, raises both energy efficiency and corrosion resistance.

To be concrete, consider an air conditioner with two characteristics: energy flow per unit of time, $f$, and cooling capacity, $c$. Further, assume that the transformation function is separable between inputs and outputs, and that inputs can be represented by an aggregate input $k$. At given input prices, $k$ can also represent the cost of producing a model $i$ with a particular bundle of characteristics, where the input price index is normalized to unity. We approximate the transformation surface as a simple multiplicative function with $k$ as the dependent variable. ${ }^{3}$ Thus at a particular point in time we have:

$$
k_{i}=\mathrm{e}^{\alpha} f_{i}^{\beta_{1}} c_{i}^{\beta_{2}}
$$

or, after taking logs,

\footnotetext{
${ }^{3}$ We also estimated translog versions. The decomposition of innovation discussed below is considerably more complex in the translog world, and we found that the translog estimation yielded similar results (Newell 1997). For notational convenience we generally suppress the model subscript $i$ in subsequent equations.
} 


$$
\ln k_{i}=\alpha+\beta_{1} \ln f_{i}+\beta_{2} \ln c_{i}
$$

Figure I illustrates a projection of the transformation surface onto the $k$ - $f$ plane for a fixed level of capacity (at two points in time). ${ }^{4}$

In this framework, product innovation is the introduction of some combination of characteristics not previously available. Thus, innovation can occur by bringing to market a characteristic bundle that was previously feasible but never offered, or it can occur by producing a model offering a combination of characteristics that was not previously technically feasible. In other words, innovation can occur by changing the composition of models offered on the existing transformation surface (which represents the set of technologically feasible models), or by offering a model on a new transformation surface that has shifted in a beneficial way.

The distinction between "movements of the curve" and "movements along the curve" is integral to our analysis, but terminology is not completely standard in this area. We use the phrase "technological change" interchangeably with "movements of the transformation surface." Technological change can be broken down further into movements of the surface that facilitate general improvement in all characteristics ("overall technological change"), and movements that tilt the curve and thereby favor some characteristics over others ("directional technological change"). We make this distinction more precise below. We use the phrase "model substitution" to describe movements along the transformation surface, that is, changes in the menu of commercially available models holding constant the set of technologically feasible models. Finally, we use the term

\footnotetext{
4 This structure on the firm's production of characteristic-differentiated product models does not stipulate which of the conceptually infinite number of possible models will actually be produced. Indeed, the analysis of firms' strategic decisions regarding locations in product space is an area of active current research (see, for example, Stavins 1995), but it is not our interest. Instead, we treat the transformation surface as characterizing the set of possible models, and we investigate which of the possible models are offered only in a general way. The fact that firm location decisions are the result of an equilibrium does raise important identification issues, which we consider later in the context of empirical estimation.
} 
"innovation" to encompass the combined effect of both changes in the product menu-movements of and along the transformation surface. ${ }^{5}$

Thus, the induced innovation hypothesis can imply that rising energy prices (1) stimulate overall technological change, (2) tilt directional technological change toward energy efficiency, and/or (3) result in model substitution toward energy efficiency. ${ }^{6}$ We allow empirically for the existence of all three phenomena.

\section{II.B. DECOMPOSITION OF CHARACTERISTICS INNOVATION}

In reality, the transformation surface for any given product is continually shifting, tilting, and changing its composition. When these changes occur simultaneously, there is no unique way to measure their separate effects. We adapt to the current context a standard approach to decomposition from the aggregate technical change literature. Figure II presents another projection of the transformation surface onto the capital cost/energy flow plane, holding constant capacity (and other characteristics, if relevant). For the time being, assume there is a single consumer whose optimal capital cost/energy flow combination at time $t_{0}$, given technical possibilities represented by $\Psi_{0}$, is at point a. The line $p_{f}^{0}$ represents the relative "price" of energy relevant for the choice of optimal energy efficiency; it is determined by the expected path of energy prices, the discount rate, and the expected intensity of usage of the capital good. Assume that at some time $t_{l}$, technical possibilities

\footnotetext{
${ }^{5}$ In this we follow Schumpeter, who used"invention" for the act of creating a new technological possibility, and "innovation" for the commercial introduction of a new technical idea. Introducing a new model that was already technically feasible would constitute innovation but not invention, whereas introducing a new model that had previously been infeasible constitutes invention and innovation. Both are to be distinguished from the third stage of Schumpeter's trichotomy, diffusion, that is, the gradual adoption by firms or individuals of commercially available products. For an empirical an anlaysis of the diffusion of energy-efficiency technologies, see Jaffe and Stavins (1995).

${ }^{6}$ The second two interpretations can readily be derived from an optimizing model of firm and consumer behavior (Newell 1997), while the first may be thought of as emerging from a satisficing or evolutionary model in which firms normally act within existing routines, but shift to new and possibly innovative modes of thinking when faced with significant changes in the economic environment.
} 
have improved, as represented by the shift of the transformation surface from $\Psi_{0}$ to $\Psi_{1}$, and that energy prices have also changed so that the price line now has the slope of $p_{f}^{1}$ instead of $p_{f}^{0}$. Accordingly, optimal energy flow and capital cost are now located at point $\mathbf{d}$.

Measured in terms of energy flow, we can decompose the improvement between points a and d into the distances labeled $\mathbf{R}, \mathbf{D}$, and $\mathbf{P}$ on the horizontal axis, which correspond respectively to the movements from $\mathbf{a}$ to $\mathbf{b}$, from $\mathbf{b}$ to $\mathbf{c}$, and from $\mathbf{c}$ to $\mathbf{d}$. Point $\mathbf{b}$ is the point on the new transformation surface that lies on a ray to the origin from the initial point $\mathbf{a}$. Hence, the movement from $\mathbf{a}$ to $\mathbf{b}$ represents equi-proportionate improvement in capital and energy costs, and the distance $\mathbf{R}$ corresponding to this movement is a measure of the rate of overall innovation. In percentage terms, it is the rate of decrease in the total cost of the good (i.e., capital cost plus energy cost). Point $\mathbf{c}$ lies at the tangency between the new transformation surface and the old price line. In the figure, point c lies to the left of point $\mathbf{b}$ because the transformation surface has become less steeply sloped, implying that if energy prices had not changed, the optimal characteristic bundle would be more energy efficient (less energy flow). Thus, the horizontal distance $\mathbf{D}$ between $\mathbf{b}$ and $\mathbf{c}$ measures the effect on energy use of the tilt in the transformation surface between time $t_{0}$ and $t_{l}$, i.e., what we call "directional technological change." Finally, point $\mathbf{d}$ is the new optimum and the movement from c to $\mathbf{d}$, which we label $\mathbf{P}$, is the "model substitution" effect (given the new technology) brought about by the change in prices from $p_{f}^{0}$ to $p_{f}^{1}$.

Algebraically, expressions for $\mathbf{R}, \mathbf{D}$, and $\mathbf{P}$ can be derived in continuous time from the firstorder conditions for a consumer's selection of the optimal capital cost and energy flow given the technological possibilities described by the transformation surface in Equation (3). ${ }^{7}$ This is given by:

\footnotetext{
${ }^{7}$ See Newell (1997) for complete derivation.
} 


$$
\frac{\dot{f}^{*}}{f^{*}}=\frac{1}{1-\beta_{1}} \cdot\left(\dot{\alpha}+\dot{\beta}_{1} \ln f^{*}+\dot{\beta}_{2} \ln c^{*}\right)+\frac{1}{1-\beta_{1}} \cdot \frac{\dot{\beta}_{1}}{\beta_{1}}-\frac{1}{1-\beta_{1}} \cdot \frac{\dot{p}_{f}}{p_{f}}
$$

where $p_{f}$ is the discounted present value of the expected stream of relative energy prices, as in Figure II. Equation (4) indicates that the optimal rate of change of energy flow is comprised of three terms: the response to the overall movement of the transformation surface; the response to changes in the slope of the surface; and the movement along the surface in response to changes in the price of energy. ${ }^{8}$

For a given capacity of the durable good, the rate of change in energy efficiency is equal to the negative of the rate of change of energy flow:

$$
\left.\frac{\dot{e}^{*}}{e^{*}}\right|_{c}=-\frac{\dot{f}^{*}}{f^{*}}
$$

Therefore, we decompose changes in energy efficiency as:

$$
\frac{\dot{e}_{t}^{*}}{e_{t}^{*}}=R_{t}+D_{t}+P_{t}
$$

where:

\footnotetext{
${ }^{8}$ The $1 /\left(1-\beta_{1}\right)$ term multiplying each of the terms on the right hand side of Equation (4) incorporates the fact that changes in $f$ are accompanied by changes in $k$ as different product models are selected from along the transformation surface. This "elasticity adjustment" has a dampening effect on the relationship between energy price changes and changes in desired energy flow.
} 


$$
R_{t}=-\frac{1}{1-\beta_{1}} \cdot\left(\dot{\alpha}+\dot{\beta}_{1} \ln f^{*}+\dot{\beta}_{2} \ln c^{*}\right)
$$

$$
D_{t}=-\frac{1}{1-\beta_{1}} \cdot \frac{\dot{\beta}_{1}}{\beta_{1}}
$$

$$
P_{t}=\frac{1}{1-\beta_{1}} \cdot \frac{\dot{p}_{f}}{p_{f}}
$$

As in Figure II, $R_{t}$ is the rate of overall innovation, a positive value for $D_{t}$ indicates innovation that is biased toward saving energy relative to saving capital costs, and $P$, represents movements in product offerings along a transformation surface due to changes in relative prices. ${ }^{9}$ We note, however, that this decomposition does not account for the effect of energy efficiency regulation on movements along the surface--an issue we address in section $\mathrm{V}$.

In reality, we observe many models being offered at any point in time, as in Figure I. This is both a blessing and a curse. It is a blessing because it facilitates econometric estimation of the transformation surface. This is what makes the empirical implementation of the induced innovation hypothesis in the characteristics setting dramatically more powerful than its antecedent in the aggregate production/cost function context. The aggregate literature observes only a series of points like $\mathbf{a}$ and $\mathbf{d}$, and attempts to infer how both the position and the slope of the transformation surface changes over time. Clearly, this is difficult to do without very strong functional form assumptions.

\footnotetext{
${ }^{9}$ We call $P$, model "substitution" because of its similarity to the concept of input substitution along a production isoquant or product substitution along a production possibility frontier, recognizing that this term is not strictly appropriate because the range of model offerings can be expanded or enriched without a new model always displacing an old one.
} 
In our microeconomic context, because at each instant there are multiple models, we can estimate the entire surface at each point in time, and separately identify changes in its position and shape. It is then possible to test whether these changes are induced by changes in energy prices and other potentially relevant factors.

On the other hand, the multiplicity of models presents a conceptual problem because we need to carry out the decomposition illustrated in Figure II for some specific bundle of characteristics at each point in time. Our solution to this problem is to construct a hypothetical model bearing the mean characteristics of all models offered, and to trace out the movements of this mean model over time. This is not fully satisfactory, however, because the mean can change through the disappearance of models without anything we would call innovation occurring. We return to this and related issues below.

\section{DATA}

Our empirical application is for three energy-intensive durable goods used for heating and cooling: room air conditioners, central air conditioners, and gas water heaters. ${ }^{10}$ The primary characteristics of all three technologies are: cooling or heating capacity, energy flow, and capital cost. Cooling/heating capacity measures the level of cooling/ heating services delivered per unit time; energy flow measures the amount of energy used per unit time; and capital cost is a measure of the real cost of producing the product or, alternatively, an index of the quantity of inputs used in production. We investigate changes in energy efficiency, which measures the cooling/heating

\footnotetext{
${ }^{10}$ A pproximately 70 percent of U.S. households own an air conditioner and 54 percent own a gas water heater (Energy Information Administration 1996, U.S. Department of Energy 1993). Operating costs represent a significant portion of the lifetime costs of these products and models are available with a variety of energy efficiency levels.
} 
service delivered per unit of energy consumed during operation; that is, capacity divided by energy flow. We also consider other important characteristics of the products.

Using the Sears catalogue (Sears, Roebuck and Co. 1958-1993) and other publicly available data sources, we compiled a database of information on 735 room air conditioner models offered for sale from 1958 through 1993; 275 central air conditioner models from 1967 through 1988; and 415 gas water heater models from 1962 through 1993. The catalogues contain a wide variety of product models over many decades, a comprehensive set of descriptive data on product characteristics, and importantly, transaction prices, as opposed to list prices (which may be subject to discount). ${ }^{11}$ Below, we describe the variables used in the analysis and summarize their construction. Table I provides descriptive statistics. ${ }^{12}$

Model characteristics. We assembled data on the cooling/heating capacity, energy flow, energy efficiency, real capital cost, and other characteristics of all models of room and central air conditioners and gas water heaters from the Sears catalogue over the 36-year period from 1958 to 1993. We also included storage capability for gas water heaters and dummy variables indicating the number of fan speeds for room air conditioners. The mean capacity of available models of all three products changed very little over the sample period, falling on average by less than 0.3 percent per year. Energy flows fell faster, leading to a net rise in the mean energy efficiency of the three products (Figure III). Central air conditioners experienced the greatest annualized rates of change

\footnotetext{
${ }^{11}$ There are, however, occasional sales on products in the Sears catalogue. See Gordon (1990) for a thorough review of the advantages and disadvantages of using various data sources for such analysis.

${ }^{12}$ To facilitate interpretation of the parameter estimates of the characteristic transformation surfaces, we normalized the time variable to equal zero in 1975 and we normalized all other purely time-series variables (i.e., energy prices and product shipments) to equal unity in 1975 , or zero after taking natural logarithms. We normalized all other variables so their normalized means equal unity, or zero after taking natural logarithms.
} 
in energy efficiency ( 2.6 percent), followed by room air conditioners ( 1.2 percent), and gas water heaters $(0.3$ percent $)$.

We constructed a measure of the real capital cost of each product model by deflating nominal unit price by an input price index for its SIC code. ${ }^{13}$ In this way, the variable also may be thought of as an index of the quantity of inputs used in production. The calculated mean capital cost of room air conditioners, central air conditioners, and gas water heaters fell by 2.2 percent, 1.8 percent, and 0.9 percent (annualized), respectively.

Inherent in this approach is an assumption that output price is proportional to production cost, or equivalently, that percentage markups have been constant over time. To the extent that this is untrue, our estimate of the rate of capital cost reductions could be biased, but in fact, the net profit margins for the manufacturers used in the analysis have changed very little over the time period of study. ${ }^{14}$ Nevertheless, we include aggregate product shipments for each technology in the transformation surfaces to control for possible markup changes, as well as possible economies of scale in production.

Relative price of energy. We constructed measures of the value to the consumer of energy flow reductions relative to capital cost reductions by dividing the Consumer Price Index for electricity (for room and central air conditioners) and natural gas (for water heaters) by the input cost

\footnotetext{
${ }^{13}$ By identifying production cost by deflating output price by an input cost index not differentiated by product model, we implicitly assume that models of different quality use the same input mix at a point in time. In addition, because the cost shares for the Divisia index are based on total cost, the resulting index of input price changes will differ from an index that was based on the input shares for the marginal unit, if the input shares change with the level of production. For details on the construction of the input cost indices, see Newell (1997).

${ }^{14}$ Average annual changes in markup have been less than 0.05 percent (Newell 1997). If the percent markup of price over marginal cost is correlated with one of the characteristics of the products, such as capacity or energy efficiency, the estimated coefficients of the surfaces could be subject to the usual omitted variable bias. Nonetheless, unless this markup changes systematically over time, it should not seriously bias the rates of change of these parameters, and the measures of innovation based on them. However, if any positive association between the percent markup and energy-efficiency was exaggerated during periods of increasing energy prices — which is plausible — then we would underestimate the induced effect of energy prices on the direction of innovation.
} 
indices described above. The relative price indices for electricity and natural gas have varied substantially over the past four decades (Figure IV).

Product labeling requirements. Title V of the Energy Policy and Conservation Act of 1975 (EPCA) requires product labels providing information on the energy efficiency, estimated annual energy costs, and operating cost ranges for similar products for 13 categories of appliances and equipment (Office of Technology Assessment 1992, United States Code of Federal Regulations 1995a). The compliance deadline was May, 1980, for room air conditioners and water heaters, but was delayed until February, 1988, for central air conditioners. The Sears catalogue includes label information in tabular form. We model the potential effect of product labeling on energy efficiency changes by allowing the coefficient on the relative price of energy to change from the pre-labeling to the post-labeling period, where the change occurs in 1981 for room air conditioners and 1977 for water heaters. ${ }^{15}$

Energy efficiency standards. The National Appliance Energy Conservation Act of 1987 (NAECA) mandated that minimum energy efficiency standards be met by room air conditioners and gas water heaters after January 1, 1990, and central air conditioners after January 1, 1992 or 1993 (United States Code of Federal Regulations 1995b). Since manufacturers did not wait until the deadline to meet the standards, we model the effect of efficiency standards for room air conditioners and gas water heaters using a dummy variable, $\Delta s$, which equals 1 for the years $1987-1990$ and 0 otherwise. In our estimation of the characteristic transformation surfaces, we use the comparable "level" of standards; that is, we let $s=0,1,2,3,4$ for $t<1987, t=1987, t=1988, t=1989$, and $t \geq 1990$,

\footnotetext{
${ }^{15}$ By multiplying price changes by the labeling dummy, we seek to represent how increased information could alter the perceived importance or value of energy efficiency improvements, potentially strengthening their relationship to energy price changes.
} 
respectively. ${ }^{16}$ We do not analyze the effect of efficiency standards on central air conditioners because the compliance deadlines were beyond the time frame of the data available to us.

\section{Estimation of Movements of the Transformation Surfaces}

We represent technological change by allowing the parameters of the transformation surfaces to change both as a function of time (autonomous technological change) and also as a function of the relative price of energy and energy efficiency standards (induced technological change). For room air conditioners, central air conditioners, and gas water heaters, respectively, we estimate the following versions of the transformation surface described by Equation (3):

$$
\begin{gathered}
\ln k_{i t}=\alpha+\beta_{1} \ln f_{i t}+\beta_{2} \ln c_{i t}+\beta_{3} 2 \text { speed }+\beta_{4} 3 \text { speed }+\varepsilon_{i t} \\
\ln k_{i t}=\alpha+\beta_{1} \ln f_{i t}+\beta_{2} \ln c_{i t}+\varepsilon_{i t} \\
\ln k_{i t}=\alpha+\beta_{1} \ln f_{i t}+\beta_{2} \ln c_{i t}+\beta_{5} \ln g_{i t}+\varepsilon_{i t}
\end{gathered}
$$

where, $k$ is capital cost, $f$ is energy flow, $c$ is cooling or heating capacity, 2 speed and 3 speed are dummy variables indicating whether a room air conditioner model had two or three fan speed settings, $g$ is storage capability in gas water heaters, $i$ indexes product models, $t$ indexes time, and $\varepsilon$ is an independently distributed error term with zero mean.

\footnotetext{
${ }^{16}$ This approach is consistent with manufacturers (and retailers) undertaking a constant rate of effort over the period from initial NAECA legislation to final implementation to meet the standards by the deadline. In practice, because models that met the standards were already available, much of this effort seems to have been directed toward the elimination of inefficient models rather than the introduction of new high-efficiency models.
} 
To represent autonomous technological change, we allow the parameters of the surfaces to vary flexibly as second-order functions of time. ${ }^{17}$ We introduce induced technological change by allowing the constant term and the coefficient on energy flow to vary as functions of the relative price of energy $p$ and the level of energy efficiency standards $s$. Since changes in these parameters over time determine the overall rate and the direction of technological change, allowing them to vary as functions of energy prices and regulation provides a direct test of the inducement hypothesis. To control for any effects of aggregate production levels on capital cost, we allow the constant term to vary as a function of product shipments, $q .{ }^{18}$ Thus, the varying coefficients of the estimated surfaces take on the following form:

$$
\begin{gathered}
\alpha=\alpha_{0}+\alpha_{1} t+\alpha_{2} t^{2}+\alpha_{3} \ln q_{t}+\alpha_{4} \ln p_{t-j}+\alpha_{5} s \\
\beta_{1}=\beta_{10}+\beta_{11} t+\beta_{12} t^{2}+\beta_{13} \ln p_{t-j}+\beta_{14} s \\
\beta_{2}=\beta_{20}+\beta_{21} t+\beta_{22} t^{2}
\end{gathered}
$$

where $t$ is time, $p$ is the relative price of energy, $s$ is the level of energy efficiency standards, and $q$ is aggregate product shipments. The subscript $j$ indicates that the associated price occurred $j$ years prior to year $t$. Based on assessments in the literature of the tooling and redesign time required to

\footnotetext{
${ }^{17}$ Both time interaction terms for the fan speed dummies for room air conditioners and for storage capability for gas water heaters were eliminated because we found them to be both very small and statistically insignificant.

${ }^{18}$ It is not clear, a priori, whether we should expect the coefficient on $\ln q$ to be positive, due to an association with demand shocks or the business cycle, or negative, due to economies of scale in production. Because shipments for the products we investigated have been generally increasing over time, we also face the difficult issue of distinguishing scale effects from technological change. We therefore do not place too much interpretative emphasis on the effect of product shipments, viewing it rather as a useful control variable along the "price-quantity" dimension.
} 
bring energy-saving product innovations to market, ${ }^{19}$ we estimate equations using the three-year lag in the relative price of energy (i.e., $j=3$ ) and the current price (i.e., $j=0$ ).

Although we do not focus on the equilibrium that determines which product models are offered in a given year, the existence of this equilibrium process raises the possibility of an endogeneity problem in using the product characteristics as regressors. We interpret the regression function as tracing out the transformation surface, which could be thought of as a "supply function" for characteristics. There is, of course, a large literature on hedonic price regression, in which model prices are regressed on characteristics, and the regression function is sometimes used as the basis for estimating a demand function for characteristics. ${ }^{20}$ It is well known that a regression of prices on characteristics embodies a variant of the classic supply/demand simultaneity problem, in which the regression coefficients are not, in general, identified as parameters of either the supply or demand function (Rosen 1974; see also Epple 1987, and Triplett 1987). The ordinary hedonics interpretation of a regression of model prices on characteristics as a demand function requires an assumption that the data are generated by heterogeneous suppliers' distinct supply functions tracing out the demand curve of homogeneous consumers. Conversely, our interpretation of the deflated price regression as a supply function requires an assumption of heterogenous consumers' distinct demand functions tracing out the supply curve of a homogenous production sector.

This latter interpretation is plausible in the current context. Indeed, all models in the sample are supplied by the same firm, although the models in Sears' catalogue span the space of available

\footnotetext{
${ }^{19}$ An Energy Information Administration (1980) study found that major tooling and redesign changes to incorporate energysaving design options require lead times of about $1 \frac{1}{2}-2$ years for a single model and longer for an entire product line. Thus, a typical cycle for introducing new appliance models can be three or more years. This time frame is consistent with other assessments in the literature of the time required to develop and bring new product innovations to market (Levin, Klevorick, Nelson, and Winter 1987).

${ }^{20}$ In particular, Gordon (1990) uses hedonics to generate quality-adjusted price indices for a large number of durable goods, including room air conditioners and gas water heaters.
} 
models. Different consumers purchase different models with different efficiencies, presumably because they have different discount rates and different anticipated intensities of usage. Further, energy efficiency is different from other characteristics that are typically the focus of hedonic analysis. In general, we expect a given consumer to have a downward sloping demand curve for a given characteristic; for example, at some point additional computer memory has little value, particularly holding constant other attributes. In contrast, the value of energy savings is essentially constant for any given discount rate and expected usage. Hence, each consumers' demand curve is infinitely elastic, so that there is unlikely to be simultaneity bias in interpreting our estimates as parameters of the supply structure.

Finally, to compensate for heteroskedasticity, we compute robust standard errors using White's (1980) method. There was no evidence of autocorrelation of residuals along the time series dimension of the estimated equations. To avoid problems associated with the potential endogeneity of aggregate shipments, we estimate the surfaces using two-stage least squares, instrumenting for the log of the quantity of shipments using levels and changes in the log of housing starts and real household income, as well as the other explanatory variables.

\section{IV.A. RESULTS OF ESTIMATION OF CHARACTERISTICS TRANSFORMATION SURFACES}

The overall results lend support to the basic validity of the model. Most of the parameters are estimated precisely; the estimated elasticities for the various characteristics all have the expected signs and reasonable magnitudes; and the coefficient on time is negative in all cases, indicating positive technological change. The basic model that the capital cost of durable goods increases with increasing energy efficiency, capacity, and other desirable characteristics is strongly supported, as is the hypothesis that the capital cost of producing a given bundle of characteristics tends to fall over 
time as a result of technological change in production techniques and product design. We also find support for the hypothesis that the direction of technological change is responsive to relative price signals and possibly government regulations.

The estimation results for both the autonomous and induced surfaces are given in Tables II, III, and IV. The three equations for induced technological change for each product provide results using the three-year lag in the relative price of energy, the contemporaneous price, and a third equation that takes one of these two equations and eliminates insignificant terms. Unless otherwise noted, the discussion focuses on the results of this last specification.

The coefficient on $\ln f\left(\right.$ i.e., $\beta_{10}$ ) measures the elasticity of capital cost with respect to energy flow in 1975; the elasticity for other years depends on the year and the magnitudes of $\beta_{11}$ and $\beta_{12}$. The elasticity is negative for all three products, as expected, indicating that reductions in energy flow come at the expense of higher capital cost, but the magnitude of this tradeoff varies significantly among the technologies.

\section{IV.B. THE RATE AND DIRECTION OF TECHNOLOGICAL CHANGE}

We decompose movements of the frontier by measuring changes along a ray to the origin (overall technological change or $R_{t}$ ), and along the new frontier to a point of tangency with an unchanged price line (directional technological change or $D_{l}$ ). Once the characteristics transformation surfaces have been estimated over time, we calculate $R_{t}$ using Equation (7) and $D_{r}$ using Equation (8); the results are provided in Table V. ${ }^{21}$ Figure V illustrates the movement of the estimated transformation surface for room air conditioners over time, revealing substantial overall

\footnotetext{
${ }^{21}$ The results are calculated using a discrete time approximation to the continuous-time equations (Newell 1997).
} 
technological change, as well as significant directional technological change, as evidenced by the changing slope.

The rate of technological change. The average annual rate of overall technological change of central air conditioners was highest ( 3.0 percent), followed by room air conditioners ( 2.1 percent), and somewhat distantly by gas water heaters $(0.8$ percent $) .{ }^{22}$ Since the rate of overall technological change corresponds to equi-proportional decreases in capital and operating cost, the estimates of overall technological change can be interpreted as rates of decrease in the total present value cost of the product, holding constant other attributes and relative prices. Thus, cumulative overall technological change in room and central air conditioners and gas water heaters of 105 percent, 88 percent, and 29 percent, imply total cost reductions in these products of 51 percent, 47 percent, and 22 percent, respectively. ${ }^{23}$ The effects of $\ln p$ and $s$ on the constant term $\left(\alpha_{4}\right.$ and $\left.\alpha_{5}\right)$ represent the influences of relative energy prices and energy-efficiency standards on the rate of overall technological change. The signs, magnitudes, and statistical significance of these coefficients do not, however, provide consistent support for there being either positive or negative effects.

The direction of technological change. The predicted changes in efficiency associated with the changing slope of the transformation surface tend to favor energy efficiency during periods of rising energy prices. All three products experienced technological change directed more toward

\footnotetext{
22 A primary determinant of $R$, is the coefficient on time $\left(\alpha_{1}\right)$, which gives the rate of decrease in capital cost in 1975, holding constant other variables at their means; the rate for other years depends on the year and the magnitude of $\alpha_{2}$. This rate of constant-quality cost reduction is related to the quality-adjusted price indices typically constructed in hedonic analyses, although it controls for changes in input prices as well as output characteristics, and is thus more a measure of technological change. The rate varies across the products from -2.7 percent for room air conditioners to -5.1 percent for central air conditioners (in 1975). As previously explained, however, we prefer to use a measure for the rate of overall technological change, $R_{t}$, that does not implicitly assume that all technological change goes toward capital cost reductions.

${ }^{23}$ The total cost reductions are found using the following relationship between cumulative technological change, $R_{t o r}$, and total cost reductions, $C_{t o r}=1-1 /\left(1+R_{t o r}\right)$.
} 
energy efficiency (i.e., $D$ was more positive) during periods of energy price increases than at other points during the study period.

All three technologies display significant autonomous slope changes. ${ }^{24}$ For room air conditioners, the autonomous component favored energy efficiency over the period as a whole, while for central air and gas water heaters it favored capital cost reduction. In all three cases this component has shifted over the course of time toward energy saving. Energy price inducements also constituted an important component of the direction of technological change for room air conditioners and somewhat less so for central air conditioners, but seemed to have little effect on the direction of technological change in gas water heaters. ${ }^{25}$ For example, the results indicate that a 10 percent increase in relative energy prices is associated with about a $0.04,0.13$, and 0.04 decrease in the absolute magnitude of the elasticity of capital cost with respect to energy flow for room air conditioners, central air conditioners, and gas water heaters, respectively.

Evidence supporting an effect of energy-efficiency standards on the direction of technological change is more mixed. The direction of technological change shifted substantially in favor of energy efficiency during the period that Federal energy efficiency standards were being implemented for room air conditioners, but not gas water heaters. ${ }^{26}$ Of course, the concern remains

\footnotetext{
${ }^{24}$ The magnitudes of the effects are at times, however, implausibly large. Most of the problem here is that the surfaces as estimated at times have relatively little curvature, so that small changes in the slope yield large predicted changes in the point of tangency.

${ }^{25}$ The effects of $\ln p$ and $s$ on the elasticity of capital cost with respect to energy flow $\left(\beta_{13}\right.$, and $\left.\beta_{14}\right)$ represent the influences of relative energy prices and energy-efficiency standards on the direction of technological change. In all equations where the effect of relative prices on the direction of technological change is statistically significant, it is also positive, providing evidence that increases in the relative price of energy are associated with technological change directed toward energyefficiency improvements. For room and central air conditioners, this effect is statistically significant using a three-year lag in the relative price of energy and is of moderate magnitude. For gas water heaters, the effect is statistically significant using the current relative price of energy, but the effect is quite small. Thus, the analysis generally supports the notion that relative price changes affect the direction of technological change.

${ }^{26}$ While the coefficient on $\operatorname{sinf}$ is not economically or statistically significant in any equations for gas water heaters, it is of sizeable magnitude and significance in most alternative specifications for room air conditioners.
} 
that the representation of changing regulatory standards by a constant time dummy is a blunt instrument that could potentially act as a proxy for factors other than energy efficiency standards that were influential during the same time period.

\section{Changes IN THE Composition of Models OfFERED}

The results of the previous section can be interpreted in terms of a thought experiment. If the position and shape of the transformation surface changed the way they did over the last several decades, but discounted expected energy prices had remained unchanged, the results say that the new point of tangency between the surface and the price line would be at substantially higher energy efficiency. As discussed earlier, the change in energy efficiency holding constant relative energy prices $(R+D)$ is a measure of how the movement of the frontier has affected energy efficiency. In this section we turn to an analysis of the movements along the frontier, i.e., changes in the feasible models that are in fact offered.

Equation (4) provides a direct prediction of the movement along the frontier that "ought" to occur given the actual change in relative energy prices. That is, given the estimated curvature of the transformation surface, we can calculate how much the point of tangency moves along the energy flow axis for any given change in relative prices. It is clear, however, that the actual changes in the mean energy efficiency over time have not conformed to the prediction of Equation (4) regarding optimal responses to changing technological possibilities and energy prices. Up to this point, it is impossible to say whether this is because the menu doesn't really respond to the changing shape of the frontier, because the choice of offerings along the frontier does not really respond to energy price changes, or because the decomposition does not account for the effect of energy efficiency 
regulation. To shed light on this issue, we perform a final set of regressions which relax some of the restrictions inherent in Equation (4).

The theory behind Equations (4) or (6) suggests that if we were to regress the rate of change of energy efficiency on $R_{b} D_{b}$ and $P_{t}$, the intercept of the regression line should be zero and the slope coefficients should be unity. These are testable restrictions; by relaxing them we can get some indication of exactly where they fail. In addition, we allow for effects on mean energy efficiency of both government labeling and minimum efficiency standards. Hence we estimate for each product a time-series regression of the form:

$$
\begin{gathered}
\Delta \ln \bar{e}_{t}=\sigma+\mu R_{t}+\xi_{t}+l_{0 t} \sum_{j=0}^{j} \tau_{0 j} \frac{1}{1-\beta_{1 t}} \Delta \ln p_{t-j}+l_{1 t} \sum_{j=0}^{j} \tau_{1 j} \frac{1}{1-\beta_{1 t}} \Delta \ln p_{t-j} \\
+\theta \Delta s_{t}+\varepsilon_{t}
\end{gathered}
$$

where the dependent variable is the rate of change in mean energy-efficiency, $t$ indicates values in year $t, \Delta$ indicates annual changes from year $t-1$ to year $t, \ln$ is the natural logarithm, $p$ is the relative price of electricity or natural gas to production inputs, $l_{0}$ is a dummy variable indicating that energyefficiency labeling was not yet in effect, $l_{l}$ is a dummy variable indicating that labeling was in effect, $\Delta s$ is a dummy variable indicating that energy-efficiency standards had been legislated but not yet achieved (i.e., $s$ equals 1 for $1987 \leq t \leq 1990$ ), and $\varepsilon$ is an independently distributed error term with zero mean. The subscript $j$ indicates that the associated price change occurred $j$ years prior to year 
To fully assess the effect of energy price changes, we compare the baseline simulations to counter-factual simulations which hold real energy prices at their 1973 levels, approximately their minimum for our study period. If the relative prices of electricity and natural gas had remained at their low 1973 levels, the model says that about one-quarter to one-half of the increase in the energyefficiency of the available menu experienced since then would not have occurred. Energy-efficiency would have been about 8 percent lower for room air conditioners, 16 percent lower for central air conditioners, and about 5 percent lower for gas water heaters had the energy price changes of the 1970s and 1980s not occurred.

Effect of energy-efficiency standards. Direct energy-efficiency standards appear to have had a modest and statistically significant positive effect on energy-efficiency changes during the compliance period from enactment of legislation to the time of the compliance deadline (1987-1990)..$^{35}$ We estimate that the mean energy efficiency of the menu of room air conditioners would have been about 7 percent lower than they were by the end of the sample period had the regulations not been imposed. The effect of standards on water heaters was similar ( 8 percent), which is substantial relative to the overall rate of innovation experienced by water heaters. Our analysis does not reveal the extent to which this occurred because inefficient models were dropped versus new efficient models added, although new, more efficient models were being added during the compliance period.

\footnotetext{
some effect. Possibly, the fact that central air is a "bigger" purchase makes consumers (and hence manufacturers) sensitive to price tradeoffs even without mandatory labeling, but this is only speculation.

${ }^{35}$ An important limitation of our approach that bears consideration, especially in the context of the effect of standards, is our reliance on changes in the mean energy efficiency of the menu as our measure of energy efficiency improvements. Obviously, the mean efficiency can rise because of the disappearance of inefficient models, without any introduction of new models. The elimination of inefficient models was, in fact, the primary intention of these regulations. Inspection of the distribution of the efficiencies of room air conditioners and gas water heaters over the time period when these standards were taking effect reveals that the primary effect was the elimination of the distribution's lower tail.
} 
$t$, where $j=0$ is the contemporaneous price and $j=\hat{j}$ is the most distant price lag included in the lag structure. $^{27}$

So, the theory says that $\mu, \xi$, and $\tau_{1}$ should each be unity. ${ }^{28}$ Our specification allows for this but does not impose it, and also allows for the possibility that labeling regulation increases the elasticity of average efficiency with respect to energy price, and that minimum efficiency regulations have an independent effect on average efficiency.

The estimation results are presented in Table VI. ${ }^{29}$ Because of the dynamic nature of the equations, as well as the existence of inducement effects on movements both of and along the surfaces, it is difficult to fully assess the empirical significance of the price and standards effects on the basis of the parameter estimates themselves. As an overall estimate of those effects, we carry out dynamic simulations in which total changes in energy efficiency are compared, with and without the historical changes in prices, and with and without standards. The results - presented in Table VII and Figure VI — are based on the parameter estimates in Table VI. ${ }^{30}$ We first carry out a "baseline" simulation that fits the model to the actual data; the baseline simulation replicates actual experience quite well, including capturing turning points in the innovation trajectory. ${ }^{31}$ We then

\footnotetext{
${ }^{27}$ Another possibility is that labeling had the effect of directly raising energy efficiency improvements, independent of price changes. Although we believe this specification is less theoretically reasonable, we tested this possibility by including a noninteractive labeling dummy variable, finding that it was small and not statistically different from zero in all three cases.

${ }^{28}$ Note that $\tau_{1}$ is the sum of the $\tau_{\mathrm{j} j}$ from $j=1$ to $j=\hat{j}$ in Equation (16), and recall that the term $1 /\left(1-\beta_{1}\right)$ that appears before the price terms in the same equation is already incorporated within the definitions of $R_{t}$ and $D_{i}$.

${ }^{29}$ The estimation results for the full distributed lag version are provided in the Appendix.

${ }^{30}$ Recall that we have allowed for inducement effects in the overall movement of the surface, the change in the slope of the surface, and the movement along the frontier. The first of these was insignificant and the second was significant in some models for some products. Hence the inducement effects we simulate for the menu itself are based on the parameter estimates from Table VI in conjunction with any induced influences of energy prices and standards on the measures of $R$ and $D$, which are in turn based on parameter estimates from Table IV.

${ }^{31}$ This is supported by a conventional quantitative measure for dynamic goodness of fit, 1- $U$, where $U$ is Theil's $U$ statistic (Theil 1961). In addition, decomposing $U$ into its component sources revealed that the vast majority of the simulation error for the three products was due to unsystematic error-a desirable property for simulation models (Newell 1997).
} 
compare the baseline simulations to counter-factual simulations that isolate the effects of energy

price changes and energy efficiency standards, as well as autonomous influences.

Effect of changes in the relative price of energy. In general, the results suggest that there is a substantial positive relationship between changes in the price of energy relative to production inputs and the rate of energy-efficiency improvements. ${ }^{32}$ We also find that there was a marked change in the responsiveness of energy-efficiency innovation to relative prices from the period before to the period after energy-efficiency labeling of room air conditioners and gas water heaters took effect. In the cases of both room air conditioners and water heaters, these parameters are statistically and economically significant for the period after energy-efficiency labeling took effect, but the effects are smaller and not significantly different from zero during the pre-labeling period. Indeed, the post-labeling effect for both products is not statistically distinguishable from the theoretically predicted value of unity. ${ }^{33}$ Labeling for central air conditioners did not take effect until after the period covered by our data, so the table presents a single price elasticity estimate; it approximates the theoretical value of unity. ${ }^{34}$

32 Three conventional methods for selecting the number of lags (i.e., the Akaike Information Criterion, the Schwarz Bayesian
Information Criterion, and the adjusted $\mathrm{R}^{2}$ ) recommended the same distributed lag structure for our estimated equations: 5
years for room air conditioners, 1 year for central air conditioners, and 3 years for gas water heaters. These results are
consistent with an Energy Information Administration (1980) study that found that major tooling and redesign changes to
incorporate energy-saving design options require lead times of about $11 / 2-2$ years for a single model and longer for an entire
product line. Thus, a typical cycle for introducing new appliance models can be three or more years. This time frame is also
consistent with other assessments in the literature of the time required to develop and bring new product innovations to market
(Levin, Klevorick, Nelson, and Winter 1987).

${ }^{33}$ The $1 /\left(1-\beta_{1}\right)$ elasticity adjustment is quite important here; the unadjusted price elasticity for hot water heaters is much lower than for air conditioners $\left(\eta_{1}=0.87,0.73\right.$, and 0.14 for room air conditioners, central air conditioners, and gas water heaters, respectively) (Newell 1997). The model implies that the relative magnitudes of these raw elasticities is expected given the less favorable capital cost tradeoff inherent in central air and gas water heater technology.

${ }^{34}$ The elasticity estimate for central air without labeling suggests that the labeling effect for the other two technologies may be due to some sectoral shift other than the labeling itself. To test this, we estimated an equation for central air conditioners with dummy variables for pre- and post-1981 observations as for the other products. Because there were no labeling requirements for central air, these periods should not differ if labeling is the true explanation for the shifts found for the other technologies. The result is that the post-labeling coefficient is higher than the pre-labeling coefficient, but the difference is small and insignificant. This suggests that while the difference we ascribe to labeling in the room air conditioner and water heater equations may be partly due to other (unobserved) factors (e.g., other information sources), labeling does seem to have 
Effects of the rate and direction of technological change. The precision and magnitudes of the parameter estimates for the influence of $R$ and $D$ on changes in mean energy efficiency do not provide any consistent support for distinguishable positive effects. This result is potentially due to a high degree of correlation between the rate and direction of innovation, as well as relatively constant rates of innovation, which are statistically difficult to distinguish from the constant term. Nonetheless, the simulations reveal that the autonomous component of energy efficiency changes (including the constant term) was significant, comprising up to 62 percent of the total change.

\section{CONCLUSION}

The re-emergence of energy efficiency as a policy concern has drawn new attention to an old question: To what extent does the innovation process respond to economic incentives, making it systematically easier over time to economize on inputs that become more expensive? A natural way to approach this question is to think of capital goods as products, and their resource-consuming properties as product characteristics. In this way, we place microeconomic structure on the induced innovation hypothesis. In principle, this structure permits econometric identification of the extent to which the pace of technological advance, the direction of technological advance, and changes in the "menu" of offered product models each respond to changes in resource prices.

Our application of this analytical framework to the evolution of three energy-using household durable goods yields several important findings. First, the substantial observed increases in the energy efficiency of two of the three products over the last several decades appear to have been associated with overall technological advance. Indeed, in the early part of the period, autonomous improvement in these products appears to have been biased away from energy-efficiency. That is, the up-front costs of the products was decreasing faster than their operating costs. But the significant 
increase in energy prices that occurred in the 1970s and 1980s had noticeable effects, slowing or reversing this process. Second, increasing energy prices had an observable effect on which technically feasible models were offered for sale. Third, this effect of energy-price increases on "model substitution" was particularly strong after product-labeling requirements went into effect. Indeed, our simulations suggest that the post-1973 energy price increases account for one-quarter to one-half of the observed improvements in the mean energy efficiency of new models offered for sale over the last two decades. Fourth and finally, government energy efficiency standards also had a significant impact on the average energy efficiency of the product menu.

The recent resurgence in interest in endogenous technological change has focused attention on the mechanisms by which economic agents' optimizing decisions affect the overall pace of technological change. But the endogeneity of the direction or composition of technological change is surely at least as significant. Further, whereas empirical implementation of endogenous growth models has been hampered by the difficulty of measuring the underlying exogenous factors that drive the system, variations in relative prices provide interesting "natural experiments" that permit empirical investigation of induced changes in the direction of technological change. We suggest that the product characteristics approach provides a useful theoretical framework in which to look at these experiments. 


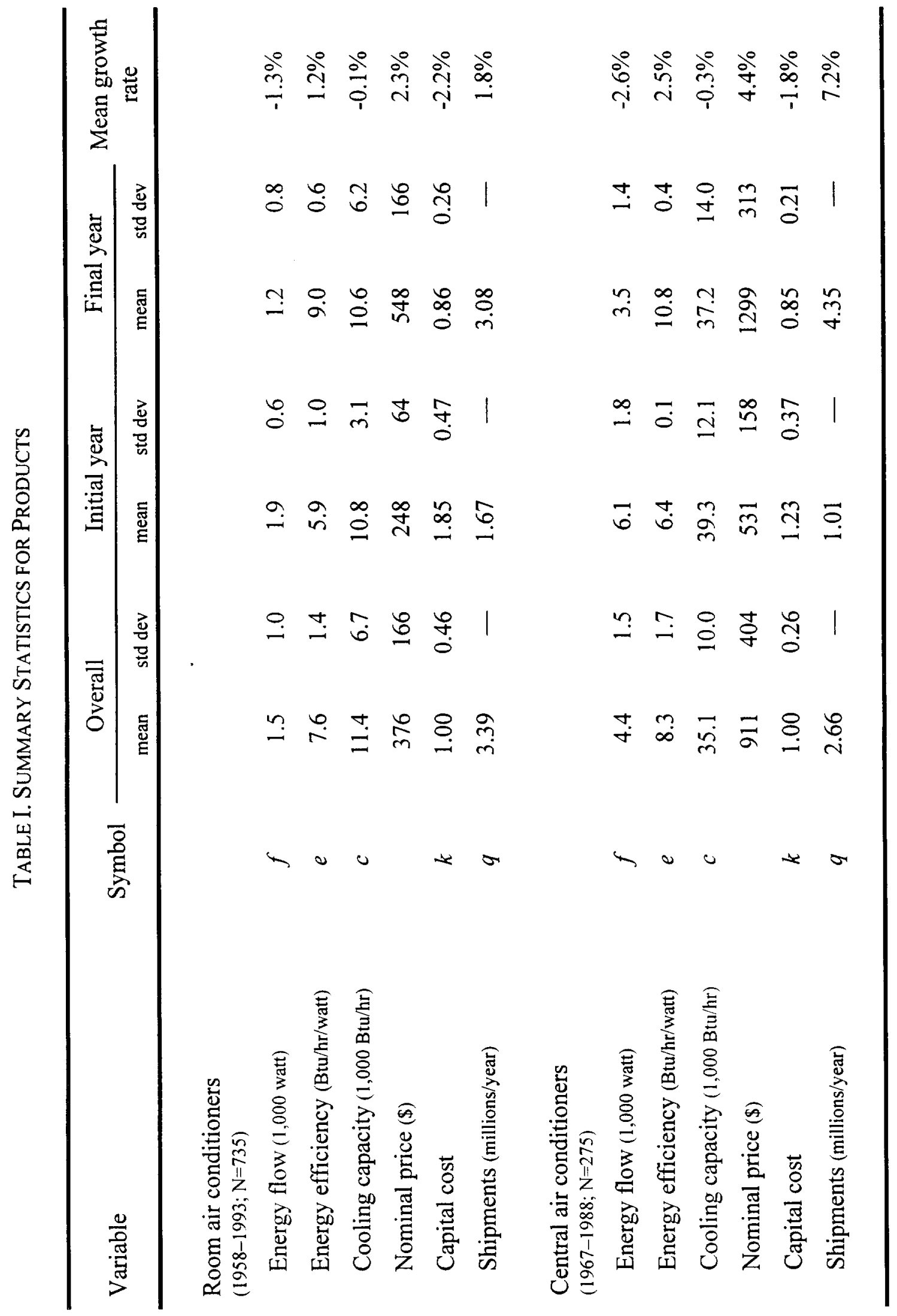




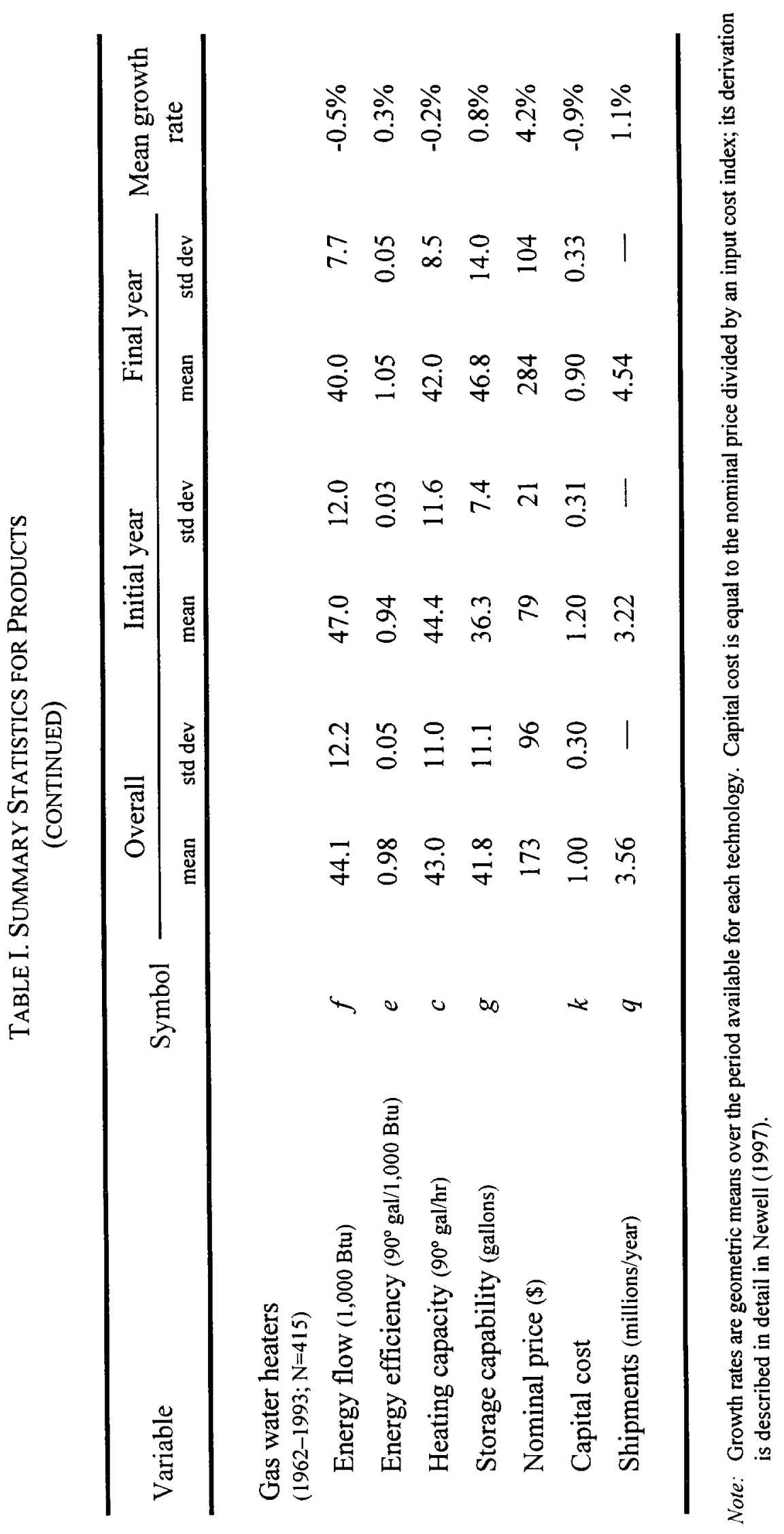


TABle II. Transformation Surface Estimates: RoOm Air CONDITIONERS

\begin{tabular}{|c|c|c|c|c|c|}
\hline \multirow{3}{*}{$\begin{array}{l}\text { Parameter } \\
\beta_{10}\end{array}$} & \multirow{3}{*}{$\begin{array}{c}\begin{array}{c}\text { Explanatory } \\
\text { variable }\end{array} \\
\ln f\end{array}$} & \multirow{3}{*}{$\begin{array}{c}\begin{array}{c}\text { Autonomous } \\
\text { innovation }\end{array} \\
\begin{array}{c}-0.387 \\
(0.027)\end{array}\end{array}$} & \multicolumn{3}{|c|}{ Induced innovation } \\
\hline & & & \multicolumn{2}{|c|}{ 3-year lag price } & \multirow{2}{*}{$\begin{array}{c}\text { current price } \\
-0.355 \\
(0.027)\end{array}$} \\
\hline & & & $\begin{array}{c}-0.362 \\
(0.026)\end{array}$ & $\begin{array}{l}-0.383 \\
(0.026)\end{array}$ & \\
\hline$\beta_{11}$ & $t \ln f$ & $\begin{array}{c}0.80 \mathrm{e}-3 \\
(2.68 \mathrm{e}-3)\end{array}$ & $\begin{array}{c}1.17 \mathrm{e}-3 \\
(2.88 \mathrm{e}-3)\end{array}$ & $\begin{array}{c}1.51 \mathrm{e}-3 \\
(2.94 \mathrm{e}-3)\end{array}$ & $\begin{array}{c}0.11 \mathrm{e}-3 \\
(3.06 \mathrm{e}-3)\end{array}$ \\
\hline$\beta_{12}$ & $t^{2} \ln f$ & $\begin{array}{c}8.33 \mathrm{e}-4 \\
(2.42 \mathrm{e}-4)\end{array}$ & $\begin{array}{c}0.70 e-4 \\
(3.14 e-4)\end{array}$ & $\begin{array}{c}3.28 \mathrm{e}-4 \\
(2.98 \mathrm{e}-4)\end{array}$ & $\begin{array}{c}6.00 \mathrm{e}-4 \\
(3.75 \mathrm{e}-4)\end{array}$ \\
\hline$\beta_{13}$ & $\ln p \ln f$ & - & $\begin{array}{c}0.410 \\
(0.125)\end{array}$ & $\begin{array}{c}0.361 \\
(0.127)\end{array}$ & $\begin{array}{l}-0.173 \\
(0.176)\end{array}$ \\
\hline$\beta_{14}$ & $\sin f$ & - & $\begin{array}{c}0.028 \\
(0.011)\end{array}$ & $\begin{array}{c}0.034 \\
(0.012)\end{array}$ & $\begin{array}{l}-0.002 \\
(0.019)\end{array}$ \\
\hline$\beta_{20}$ & $\ln c$ & $\begin{array}{c}0.919 \\
(0.028)\end{array}$ & $\begin{array}{c}0.914 \\
(0.027)\end{array}$ & $\begin{array}{c}0.937 \\
(0.027)\end{array}$ & $\begin{array}{c}0.889 \\
(0.027)\end{array}$ \\
\hline$\beta_{21}$ & $t \ln c$ & $\begin{array}{l}-2.73 e-3 \\
(2.95 e-3)\end{array}$ & $\begin{array}{l}-1.04 \mathrm{e}-3 \\
(3.05 \mathrm{e}-3)\end{array}$ & $\begin{array}{l}-1.16 \mathrm{e}-3 \\
(3.10 \mathrm{e}-3)\end{array}$ & $\begin{array}{l}-0.35 e-3 \\
(0.29 e-3)\end{array}$ \\
\hline$\beta_{22}$ & $t^{2} \ln c$ & $\begin{array}{l}-6.78 \mathrm{e}-4 \\
(2.68 \mathrm{e}-4)\end{array}$ & $\begin{array}{l}-5.90 e-4 \\
(2.93 e-4)\end{array}$ & $\begin{array}{l}-8.69 e-4 \\
(2.75 e-4)\end{array}$ & $\begin{array}{l}-3.53 \mathrm{e}-4 \\
(2.89 \mathrm{e}-4)\end{array}$ \\
\hline$\beta_{3}$ & 2-speed & $\begin{array}{c}0.197 \\
(0.016)\end{array}$ & $\begin{array}{c}0.202 \\
(0.016)\end{array}$ & $\begin{array}{c}0.201 \\
(0.016)\end{array}$ & $\begin{array}{c}0.200 \\
(0.016)\end{array}$ \\
\hline$\beta_{4}$ & 3-speed & $\begin{array}{c}0.300 \\
(0.016)\end{array}$ & $\begin{array}{c}0.299 \\
(0.016)\end{array}$ & $\begin{array}{c}0.298 \\
(0.016)\end{array}$ & $\begin{array}{c}0.302 \\
(0.016)\end{array}$ \\
\hline$\alpha_{0}$ & constant & $\begin{array}{l}-0.215 \\
(0.017)\end{array}$ & $\begin{array}{l}-0.234 \\
(0.019)\end{array}$ & $\begin{array}{l}-0.220 \\
(0.016)\end{array}$ & $\begin{array}{l}-0.235 \\
(0.017)\end{array}$ \\
\hline$\alpha_{1}$ & $t$ & $\begin{array}{l}-0.026 \\
(0.001)\end{array}$ & $\begin{array}{l}-0.026 \\
(0.001)\end{array}$ & $\begin{array}{l}-0.027 \\
(0.001)\end{array}$ & $\begin{array}{l}-0.027 \\
(0.001)\end{array}$ \\
\hline$\alpha_{2}$ & $t^{2}$ & $\begin{array}{c}1.05 \mathrm{e}-3 \\
(0.19 \mathrm{e}-3)\end{array}$ & $\begin{array}{c}1.05 \mathrm{e}-3 \\
(0.19 \mathrm{e}-3)\end{array}$ & $\begin{array}{c}0.93 \mathrm{e}-3 \\
(0.06 \mathrm{e}-3)\end{array}$ & $\begin{array}{c}0.98 \mathrm{e}-3 \\
(0.15 \mathrm{e}-3)\end{array}$ \\
\hline$\alpha_{3}$ & $\ln q$ & $\begin{array}{l}-0.083 \\
(0.024)\end{array}$ & $\begin{array}{l}-0.083 \\
(0.024)\end{array}$ & $\begin{array}{l}-0.102 \\
(0.016)\end{array}$ & $\begin{array}{l}-0.088 \\
(0.021)\end{array}$ \\
\hline$\alpha_{4}$ & $\ln p$ & - & $\begin{array}{c}0.043 \\
(0.088)\end{array}$ & - & $\begin{array}{c}0.108 \\
(0.112)\end{array}$ \\
\hline \multirow[t]{3}{*}{$\alpha_{5}$} & $s$ & - & $\begin{array}{l}-0.016 \\
(0.010)\end{array}$ & - & $\begin{array}{l}-0.011 \\
(0.010)\end{array}$ \\
\hline & \# observations & 735 & 735 & 735 & 735 \\
\hline & $\mathrm{R}^{2}$ & 0.96 & 0.96 & 0.96 & 0.96 \\
\hline
\end{tabular}

Note: Dependent variable is the $\log$ of capital $\operatorname{cost}(\ln k)$. Variables are described in more detail in Table I. Estimation method is two-stage least squares. Robust standard errors are reported in parentheses. 
Table III. Transformation Surface Estimates: Central Air Conditioners

\begin{tabular}{|c|c|c|c|c|c|}
\hline \multirow{3}{*}{$\begin{array}{l}\text { Parameter } \\
\beta_{10}\end{array}$} & \multirow{3}{*}{$\begin{array}{c}\begin{array}{c}\text { Explanatory } \\
\text { variable }\end{array} \\
\text { lnf }\end{array}$} & \multirow{3}{*}{$\begin{array}{c}\begin{array}{c}\text { Autonomous } \\
\text { innovation }\end{array} \\
-1.247 \\
(0.077)\end{array}$} & \multicolumn{3}{|c|}{ Induced innovation } \\
\hline & & & \multicolumn{2}{|c|}{ 3-year lag price } & \multirow{2}{*}{$\begin{array}{c}\text { current price } \\
-1.262 \\
(0.077)\end{array}$} \\
\hline & & & $\begin{array}{l}-1.205 \\
(0.087)\end{array}$ & $\begin{array}{l}-1.177 \\
(0.082)\end{array}$ & \\
\hline$\beta_{11}$ & $t \ln f$ & $\begin{array}{l}-0.103 \\
(0.014)\end{array}$ & $\begin{array}{l}-0.107 \\
(0.016)\end{array}$ & $\begin{array}{l}-0.103 \\
(0.014)\end{array}$ & $\begin{array}{l}-0.098 \\
(0.015)\end{array}$ \\
\hline$\beta_{12}$ & $t^{2} \ln f$ & $\begin{array}{c}4.87 \mathrm{e}-3 \\
(1.41 \mathrm{e}-3)\end{array}$ & $\begin{array}{c}4.04 \mathrm{e}-3 \\
(2.14 \mathrm{e}-3)\end{array}$ & $\begin{array}{c}2.81 \mathrm{e}-3 \\
(1.67 \mathrm{e}-3)\end{array}$ & $\begin{array}{c}5.34 \mathrm{e}-3 \\
(1.34 \mathrm{e}-3)\end{array}$ \\
\hline$\beta_{13}$ & $\ln p \ln f$ & - & $\begin{array}{c}0.968 \\
(0.566)\end{array}$ & $\begin{array}{c}1.291 \\
(0.558)\end{array}$ & $\begin{array}{l}-0.280 \\
(0.380)\end{array}$ \\
\hline$\beta_{20}$ & $\ln c$ & $\begin{array}{c}1.978 \\
(0.079)\end{array}$ & $\begin{array}{c}1.991 \\
(0.083)\end{array}$ & $\begin{array}{c}1.978 \\
(0.078)\end{array}$ & $\begin{array}{c}1.988 \\
(0.079)\end{array}$ \\
\hline$\beta_{21}$ & $t \ln c$ & $\begin{array}{c}0.101 \\
(0.013)\end{array}$ & $\begin{array}{c}0.107 \\
(0.015)\end{array}$ & $\begin{array}{c}0.105 \\
(0.014)\end{array}$ & $\begin{array}{c}0.098 \\
(0.014)\end{array}$ \\
\hline$\beta_{22}$ & $t^{2} \ln c$ & $\begin{array}{l}-4.43 \mathrm{e}-3 \\
(1.41 \mathrm{e}-3)\end{array}$ & $\begin{array}{l}-5.26 \mathrm{e}-3 \\
(1.80 \mathrm{e}-3)\end{array}$ & $\begin{array}{l}-4.60 e-3 \\
(1.42 e-3)\end{array}$ & $\begin{array}{l}-4.71 \mathrm{e}-3 \\
(1.40 \mathrm{e}-3)\end{array}$ \\
\hline$\alpha_{0}$ & constant & $\begin{array}{c}0.086 \\
(0.010)\end{array}$ & $\begin{array}{c}0.064 \\
(0.018)\end{array}$ & $\begin{array}{c}0.086 \\
(0.010)\end{array}$ & $\begin{array}{c}0.095 \\
(0.011)\end{array}$ \\
\hline$\alpha_{1}$ & $t$ & $\begin{array}{l}-0.051 \\
(0.004)\end{array}$ & $\begin{array}{l}-0.055 \\
(0.005)\end{array}$ & $\begin{array}{l}-0.052 \\
(0.004)\end{array}$ & $\begin{array}{l}-0.057 \\
(0.005)\end{array}$ \\
\hline$\alpha_{2}$ & $t^{2}$ & $\begin{array}{l}-1.48 \mathrm{e}-3 \\
(0.32 \mathrm{e}-3)\end{array}$ & $\begin{array}{l}-0.64 \mathrm{e}-3 \\
(0.65 \mathrm{e}-3)\end{array}$ & $\begin{array}{l}-1.49 \mathrm{e}-3 \\
(0.31 \mathrm{e}-3)\end{array}$ & $\begin{array}{l}-1.39 e-3 \\
(0.32 e-3)\end{array}$ \\
\hline$\alpha_{3}$ & $\ln q$ & $\begin{array}{c}0.320 \\
(0.055)\end{array}$ & $\begin{array}{c}0.385 \\
(0.082)\end{array}$ & $\begin{array}{c}0.339 \\
(0.055)\end{array}$ & $\begin{array}{c}0.377 \\
(0.067)\end{array}$ \\
\hline \multirow[t]{3}{*}{$\alpha_{4}$} & $\ln p$ & - & $\begin{array}{l}-0.421 \\
(0.286)\end{array}$ & - & $\begin{array}{c}0.214 \\
(0.175)\end{array}$ \\
\hline & \# observations & 275 & 275 & 275 & 275 \\
\hline & $\mathrm{R}^{2}$ & 0.90 & 0.90 & 0.90 & 0.90 \\
\hline
\end{tabular}

Note: Dependent variable is the $\log$ of capital $\operatorname{cost}(\ln k)$. Variables are described in more detail in Table I. Estimation method is two-stage least squares. Robust standard errors are reported in parentheses. 
TABle IV. Transformation Surface Estimates: Gas Water Heaters

\begin{tabular}{|c|c|c|c|c|c|}
\hline \multirow{3}{*}{$\begin{array}{l}\text { Parameter } \\
\beta_{10}\end{array}$} & \multirow{3}{*}{$\begin{array}{c}\begin{array}{c}\text { Explanatory } \\
\text { variable }\end{array} \\
\ln f\end{array}$} & \multirow{3}{*}{$\begin{array}{l}\text { Autonomous } \\
\text { innovation } \\
\begin{array}{c}-3.918 \\
(0.235)\end{array}\end{array}$} & \multicolumn{3}{|c|}{ Induced innovation } \\
\hline & & & \multirow{2}{*}{$\begin{array}{r}3 \text {-year lag price } \\
-3.829 \\
(0.267)\end{array}$} & \multicolumn{2}{|c|}{ current price } \\
\hline & & & & $\begin{array}{l}-4.026 \\
(0.298)\end{array}$ & $\begin{array}{l}-3.983 \\
(0.225)\end{array}$ \\
\hline$\beta_{11}$ & $\ln f$ & $\begin{array}{l}-0.055 \\
(0.032)\end{array}$ & $\begin{array}{l}-0.074 \\
(0.023)\end{array}$ & $\begin{array}{l}-0.080 \\
(0.032)\end{array}$ & $\begin{array}{l}-0.074 \\
(0.029)\end{array}$ \\
\hline$\beta_{12}$ & $t^{2} \ln f$ & $\begin{array}{c}0.012 \\
(0.002)\end{array}$ & $\begin{array}{c}0.013 \\
(0.002)\end{array}$ & $\begin{array}{c}0.012 \\
(0.002)\end{array}$ & $\begin{array}{c}0.013 \\
(0.002)\end{array}$ \\
\hline$\beta_{13}$ & $\ln p \ln f$ & - & $\begin{array}{l}-0.056 \\
(0.263)\end{array}$ & $\begin{array}{c}0.736 \\
(0.255)\end{array}$ & $\begin{array}{c}0.413 \\
(0.137)\end{array}$ \\
\hline$\beta_{14}$ & $s \ln f$ & - & $\begin{array}{l}-0.079 \\
(0.058)\end{array}$ & $\begin{array}{c}0.088 \\
(0.066)\end{array}$ & - \\
\hline$\beta_{20}$ & $\ln c$ & $\begin{array}{c}4.670 \\
(0.238)\end{array}$ & $\begin{array}{c}4.557 \\
(0.271)\end{array}$ & $\begin{array}{c}4.693 \\
(0.299)\end{array}$ & $\begin{array}{c}4.669 \\
(0.230)\end{array}$ \\
\hline$\beta_{21}$ & $t \ln c$ & $\begin{array}{c}0.071 \\
(0.032)\end{array}$ & $\begin{array}{c}0.094 \\
(0.023)\end{array}$ & $\begin{array}{c}0.079 \\
(0.031)\end{array}$ & $\begin{array}{c}0.080 \\
(0.029)\end{array}$ \\
\hline$\beta_{22}$ & $t^{2} \ln c$ & $\begin{array}{l}-0.011 \\
(0.002)\end{array}$ & $\begin{array}{l}-0.012 \\
(0.002)\end{array}$ & $\begin{array}{l}-0.011 \\
(0.002)\end{array}$ & $\begin{array}{l}-0.012 \\
(0.002)\end{array}$ \\
\hline$\beta_{5}$ & Ing & $\begin{array}{c}0.381 \\
(0.024)\end{array}$ & $\begin{array}{c}0.383 \\
(0.025)\end{array}$ & $\begin{array}{c}0.387 \\
(0.024)\end{array}$ & $\begin{array}{c}0.386 \\
(0.024)\end{array}$ \\
\hline$\alpha_{0}$ & constant & $\begin{array}{l}-0.006 \\
(0.012)\end{array}$ & $\begin{array}{l}-0.010 \\
(0.012)\end{array}$ & $\begin{array}{c}0.014 \\
(0.016)\end{array}$ & $\begin{array}{c}0.005 \\
(0.012)\end{array}$ \\
\hline$\alpha_{1}$ & $t$ & $\begin{array}{l}-0.018 \\
(0.002)\end{array}$ & $\begin{array}{l}-0.014 \\
(0.003)\end{array}$ & $\begin{array}{l}-0.014 \\
(0.003)\end{array}$ & $\begin{array}{l}-0.017 \\
(0.002)\end{array}$ \\
\hline$\alpha_{2}$ & $t^{2}$ & $\begin{array}{c}1.156 \mathrm{e}-4 \\
(1.05 \mathrm{e}-4)\end{array}$ & $\begin{array}{c}4.02 e-4 \\
(2.37 e-4)\end{array}$ & $\begin{array}{c}2.51 \mathrm{e}-4 \\
(2.14 \mathrm{e}-4)\end{array}$ & $\begin{array}{c}0.27 e-4 \\
(1.01 e-4)\end{array}$ \\
\hline$\alpha_{3}$ & $\ln q$ & $\begin{array}{c}0.640 \\
(0.092)\end{array}$ & $\begin{array}{c}0.594 \\
(0.103)\end{array}$ & $\begin{array}{c}0.550 \\
(0.103)\end{array}$ & $\begin{array}{c}0.606 \\
(0.092)\end{array}$ \\
\hline$\alpha_{4}$ & $\ln p$ & - & $\begin{array}{l}-0.073 \\
(0.065)\end{array}$ & $\begin{array}{l}-0.063 \\
(0.069)\end{array}$ & - \\
\hline \multirow[t]{3}{*}{$\alpha_{5}$} & $s$ & - & $\begin{array}{l}-0.025 \\
(0.015)\end{array}$ & $\begin{array}{l}-0.019 \\
(0.018)\end{array}$ & - \\
\hline & \# observations & 415 & 415 & 415 & 415 \\
\hline & $\mathrm{R}^{2}$ & 0.92 & 0.92 & 0.92 & 0.92 \\
\hline
\end{tabular}

Note: Dependent variable is the $\log$ of capital $\operatorname{cost}(\ln k)$. Variables are described in more detail in Table 1 . Estimation method is two-stage least squares. Robust standard errors are reported in parentheses. 
Table V. Estimated Decomposition of Product InNovation

\begin{tabular}{lccccc}
\hline & \multicolumn{3}{c}{ Mean annul growth rate } & $\begin{array}{c}\text { Cumulative } \\
\text { growth }\end{array}$ \\
\cline { 2 - 5 } & $1960-1969$ & $1970-1979$ & $1980-1989$ & Overall & \\
\hline Room air conditioners & & & & \\
Rate of innovation & $3.8 \%$ & $2.0 \%$ & $1.0 \%$ & $2.1 \%$ & $105.0 \%$ \\
Direction of innovation & $-4.6 \%$ & $-0.5 \%$ & $8.3 \%$ & $0.6 \%$ & $26.2 \%$ \\
"Substitution" & $-1.9 \%$ & $-0.2 \%$ & $0.6 \%$ & $-0.2 \%$ & $-8.2 \%$ \\
Central air conditioners & - & & & & \\
Rate of innovation & - & $3.1 \%$ & $2.9 \%$ & $3.0 \%$ & $87.5 \%$ \\
Direction of innovation & - & $-5.5 \%$ & $-0.3 \%$ & $-3.5 \%$ & $-52.8 \%$ \\
"Substitution", & - & $-0.2 \%$ & $0.4 \%$ & $0.1 \%$ & $1.4 \%$ \\
Water heaters & & & & & \\
Rate of innovation & $1.0 \%$ & $0.4 \%$ & $1.0 \%$ & $0.8 \%$ & $28.5 \%$ \\
Direction of innovation & $-6.8 \%$ & $-0.4 \%$ & $1.5 \%$ & $-0.2 \%$ & $-5.3 \%$ \\
"Substitution" & $-0.9 \%$ & $0.6 \%$ & $0.0 \%$ & $0.1 \%$ & $3.3 \%$ \\
\hline
\end{tabular}

Note: Growth rates are geometric means over the period available for each technology. Comparisons of cumulative growth should take into account that these are computed over the different periods available for each technology (i.e., 1958-1993 for room air conditioners, 1967-1988 for central air conditioners, and 1962-1993 for gas water heaters). 
TABle VI. Factors AfFecting Changes in ENERgy EfFicienCy

\begin{tabular}{|c|c|c|c|c|c|}
\hline Parameter & $\begin{array}{c}\text { Explanatory } \\
\text { variable }\end{array}$ & Description & $\begin{array}{l}\text { Room air } \\
\text { conditioners }\end{array}$ & $\begin{array}{l}\text { Central air } \\
\text { conditioners }\end{array}$ & $\begin{array}{c}\text { Gas water } \\
\text { heaters }\end{array}$ \\
\hline$\eta_{0}$ & $\frac{1}{1-\beta_{1}} l_{0} \Delta \ln p$ & $\begin{array}{l}\text { pre-labeling } \\
\text { price effect }\end{array}$ & $\begin{array}{c}0.001 \\
(0.630)\end{array}$ & $\begin{array}{c}1.394 \\
(0.423)\end{array}$ & $\begin{array}{c}0.158 \\
(0.742)\end{array}$ \\
\hline$\eta_{1}$ & $\frac{1}{1-\beta_{1}} l_{1} \Delta \ln p$ & $\begin{array}{l}\text { post-labeling } \\
\text { price effect }\end{array}$ & $\begin{array}{c}1.175 \\
(0.391)\end{array}$ & - & $\begin{array}{c}0.658 \\
(0.325)\end{array}$ \\
\hline$\theta$ & $\Delta s$ & standards & $\begin{array}{c}0.024 \\
(0.025)\end{array}$ & - & $\begin{array}{c}0.018 \\
(0.008)\end{array}$ \\
\hline$\mu$ & $R$, & $\begin{array}{c}\text { rate of } \\
\text { innovation }\end{array}$ & $\begin{array}{c}0.055 \\
(0.417)\end{array}$ & $\begin{array}{c}0.844 \\
(0.882)\end{array}$ & $\begin{array}{l}-2.835 \\
(3.454)\end{array}$ \\
\hline$\xi$ & $D$ & $\begin{array}{l}\text { direction of } \\
\text { innovation }\end{array}$ & $\begin{array}{l}-0.053 \\
(0.145)\end{array}$ & $\begin{array}{c}0.047 \\
(0.059)\end{array}$ & $\begin{array}{c}0.728 \\
(0.982)\end{array}$ \\
\hline \multirow[t]{3}{*}{$\sigma$} & constant & & $\begin{array}{c}0.007 \\
(0.007)\end{array}$ & $\begin{array}{c}0.001 \\
(0.026)\end{array}$ & $\begin{array}{c}0.009 \\
(0.010)\end{array}$ \\
\hline & & \# observations & 35 & 21 & 31 \\
\hline & $1-U$ & goodness of fit & 0.67 & 0.66 & 0.61 \\
\hline
\end{tabular}

Note: Dependent variable is the rate of change of mean energy efficiency $(\Delta \ln \vec{e})$. Estimation method is ordinary least squares. Robust standard errors are reported in parentheses. $U$ is Theil's $U$ statistic, where $1-U$ is a measure of dynamic goodness of fit. See Table ? in the Appendix for parameter estimates of the individual distributed lag price effects. 


\section{Table VII. Historical EfFects of Price Changes and Efficiency StandardS ON ENERGY-EFFICIENCY (1973-1993)}

(Historical simulations of cumulative percent change in energy efficiency)

\begin{tabular}{|c|c|c|c|c|c|c|}
\hline & \multicolumn{2}{|c|}{ Room air conditioners } & \multicolumn{2}{|c|}{ Central air conditioners } & \multicolumn{2}{|c|}{ Water heaters } \\
\hline & $\begin{array}{l}\text { Relative } \\
\text { to } 1973\end{array}$ & $\begin{array}{l}\text { Share of total } \\
\text { change }\end{array}$ & $\begin{array}{l}\text { Relative } \\
\text { to } 1973\end{array}$ & $\begin{array}{c}\text { Share of } \\
\text { total change }\end{array}$ & $\begin{array}{l}\text { Relative } \\
\text { to } 1973\end{array}$ & $\begin{array}{c}\text { Share of } \\
\text { total change }\end{array}$ \\
\hline $\begin{array}{l}\text { Total change }(\%) \\
\text { (baseline) }\end{array}$ & $\begin{array}{l}29.7 \\
(4.5)\end{array}$ & - & $\begin{array}{l}58.9 \\
(3.5)\end{array}$ & - & $\begin{array}{l}11.2 \\
(3.4)\end{array}$ & - \\
\hline $\begin{array}{l}\text { Price-induced } \\
\text { portion (\%) }\end{array}$ & $\begin{array}{c}8.2 \\
(5.0)\end{array}$ & 28 & $\begin{array}{l}16.1 \\
(5.0)\end{array}$ & 27 & $\begin{array}{c}5.3 \\
(2.4)\end{array}$ & 47 \\
\hline $\begin{array}{l}\text { Standards-induced } \\
\text { portion }(\%)\end{array}$ & $\begin{array}{c}7.1 \\
(3.1)\end{array}$ & 24 & - & - & $\begin{array}{c}7.7 \\
(1.7)\end{array}$ & 69 \\
\hline $\begin{array}{l}\text { Autonomous } \\
\text { portion }(\%)\end{array}$ & $\begin{array}{l}12.7 \\
(2.7)\end{array}$ & 43 & $\begin{array}{l}36.8 \\
(3.7)\end{array}$ & 62 & $\begin{array}{l}-1.5 \\
(1.7)\end{array}$ & -13 \\
\hline
\end{tabular}

Note: The baseline simulation uses the coefficient estimates from Table VI to estimate the cumulative change in energyefficiency from 1973-1993, assuming energy prices and efficiency standards took their historical values (simulations for central air conditioners extend only to 1988). We decompose the total change into price-induced, standardsinduced, and autonomous portions using the parts of the estimated model corresponding to these effects, and including any induced influences on the movement of the transformation surfaces. The portions do not sum to the total change due to the non-linear nature of the model. Standard errors are reported in parentheses. 
Figure I. INNOVATION IN THE CHARACTERISTICS TRANSFormation SURFACE

Capital cost $(k)$

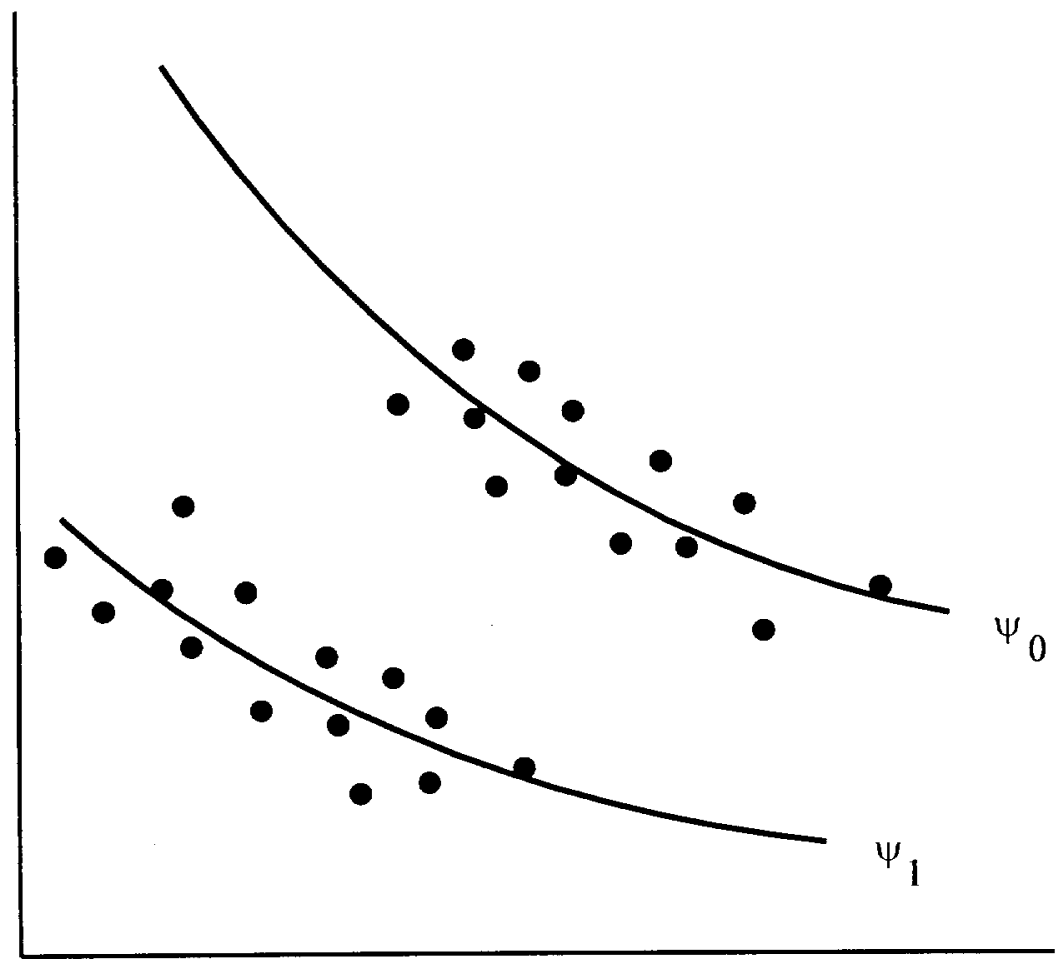

Energy flow $(f)$ 
FiguRE II. DECOMPOSITION OF CHARACTERISTICS INNOVATION

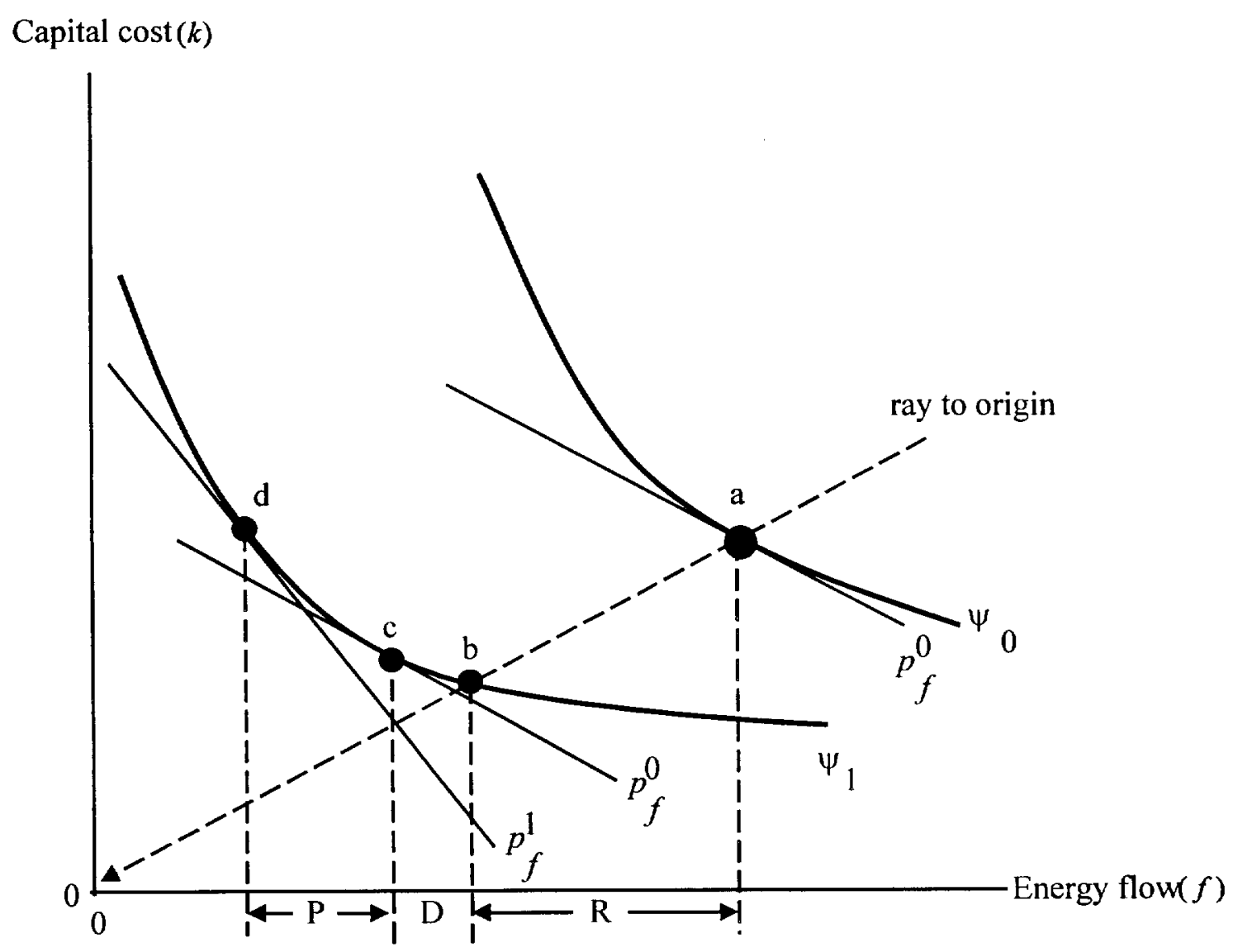


Figure III. Changes In ENERgy EfFICIENCY

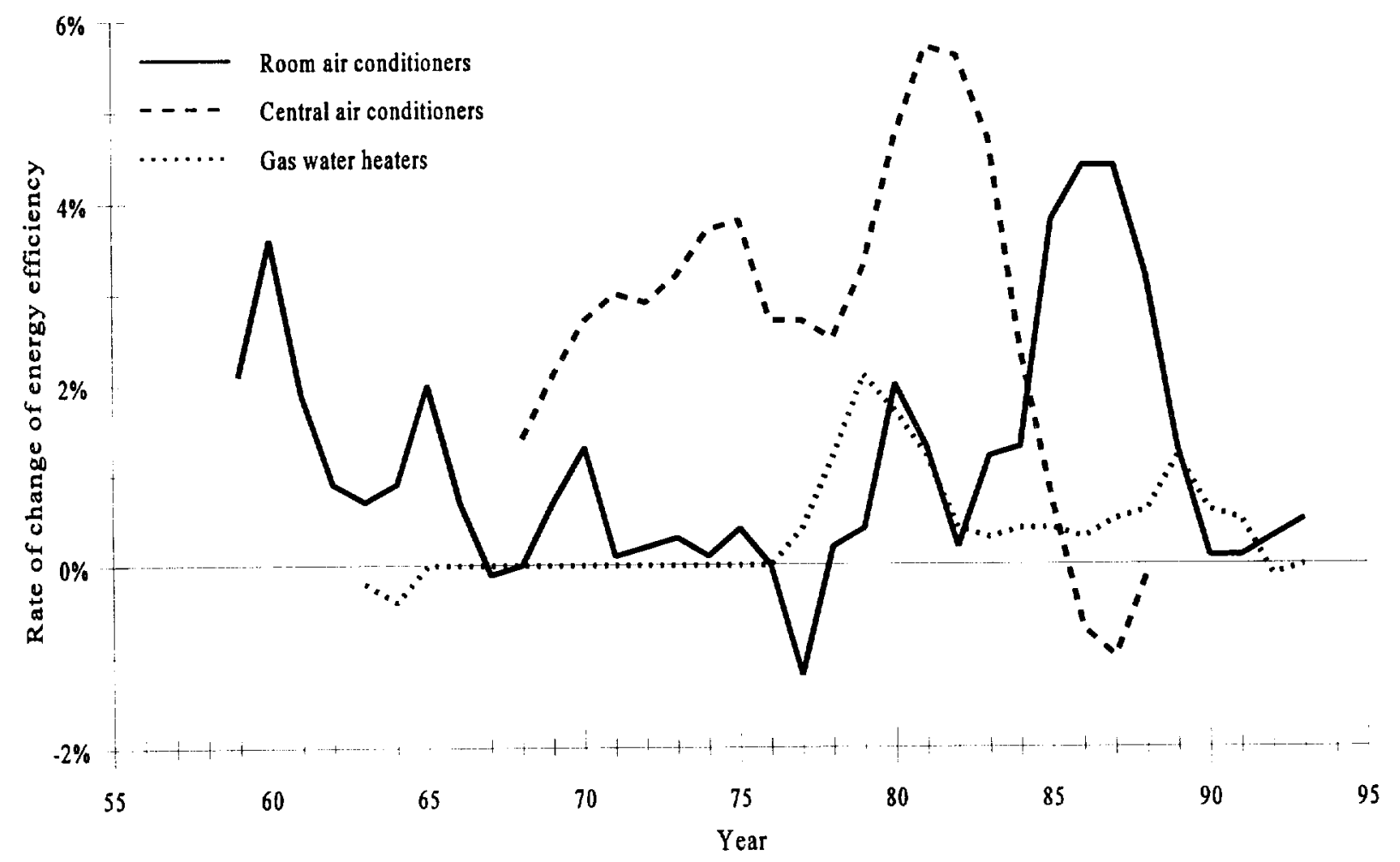

Note: The figures shows a three-year moving average of the annual rate of change of mean energy efficiency. 
Figure IV. Changes in Electricity and Natural Gas Prices

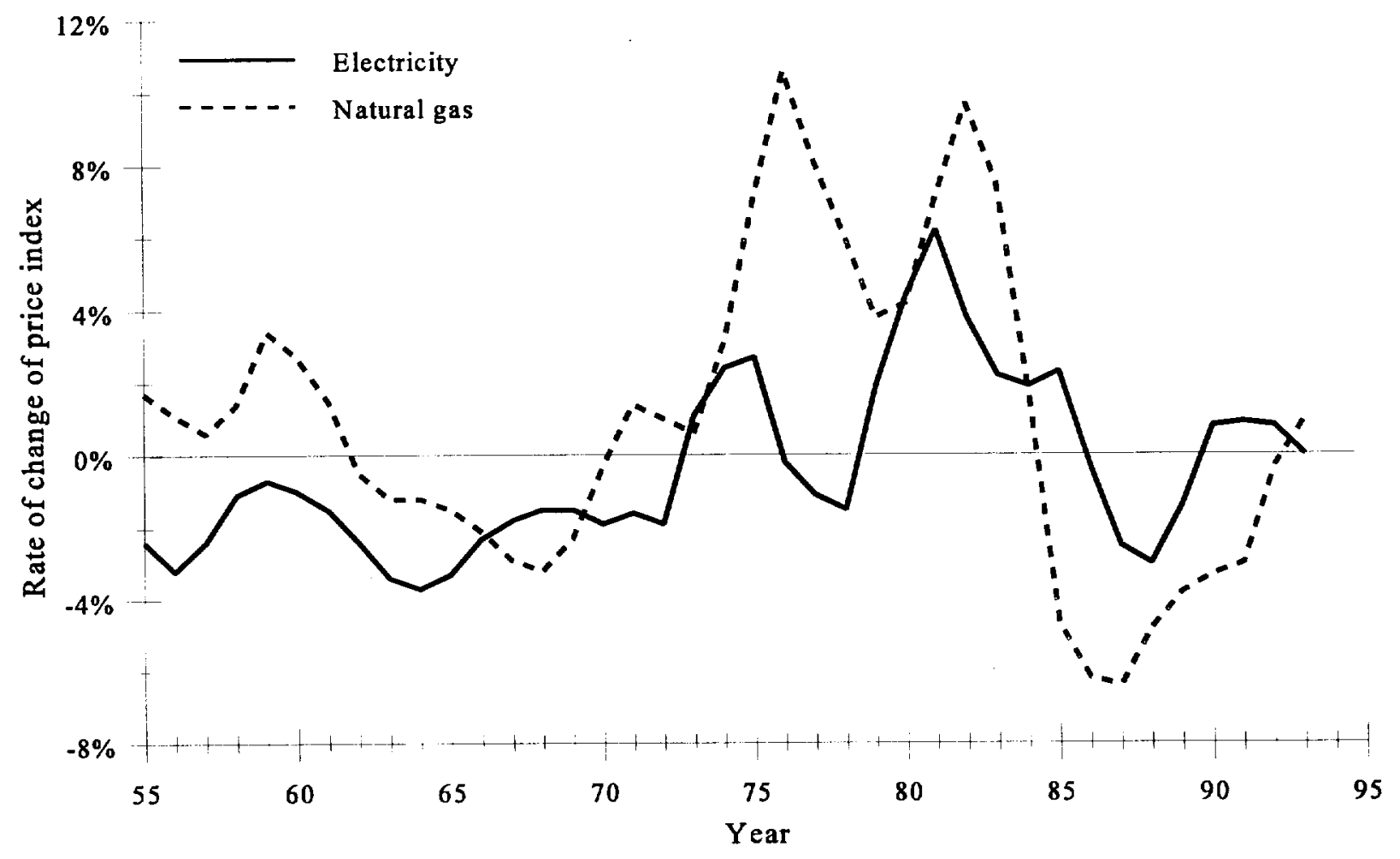

Note: $\quad$ Figure shows a three-year moving average of the rate of change of the price index. See text and Newell (1997) for detail on data construction. 


\section{FIGURE V. INNOVATION IN CHARACTERISTICS TRANSFORMATION SURFACE: ROOM AIR CONDITIONERS}

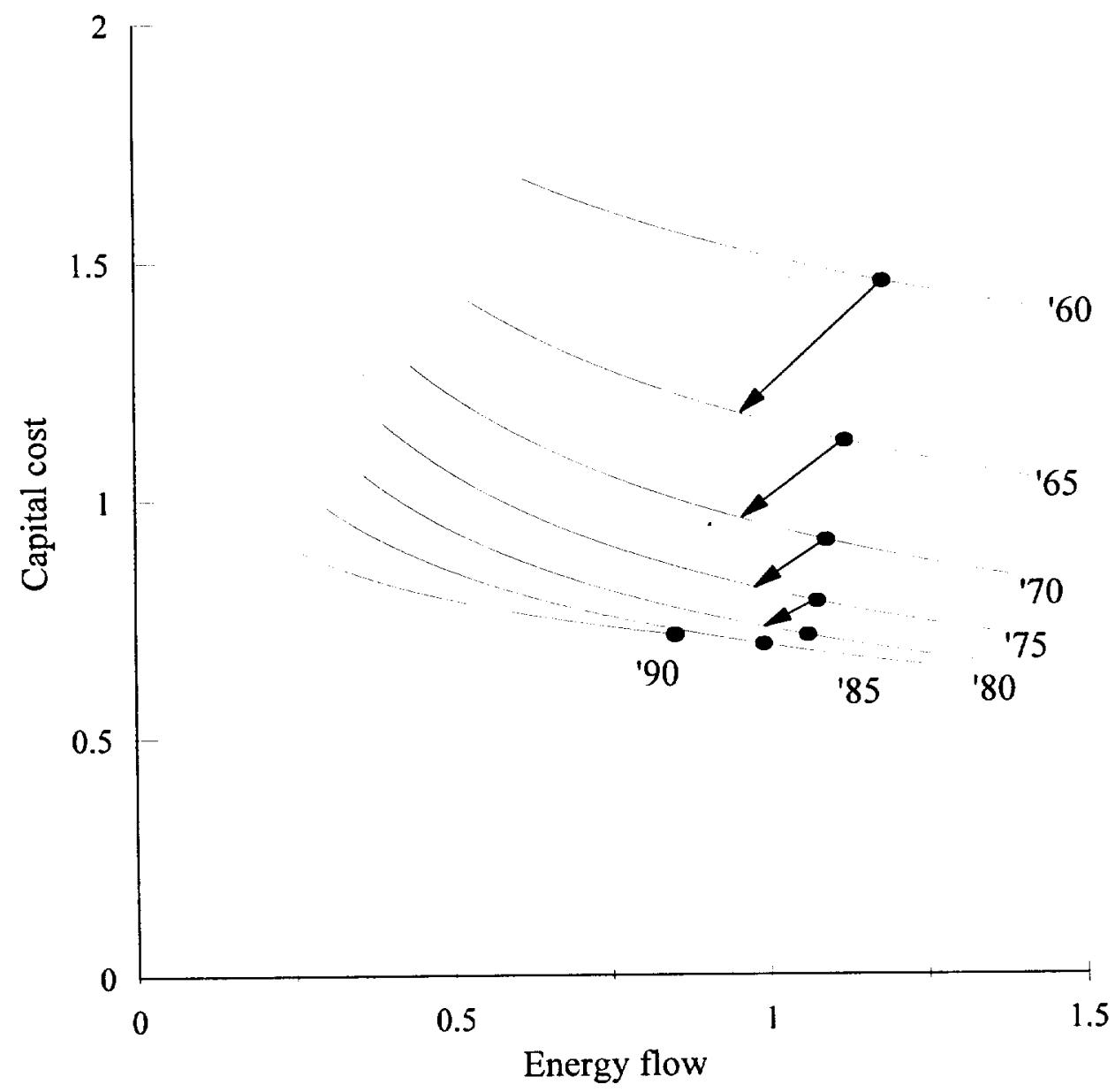

Note: Figure illustrates the estimated transformation surfaces over 5-year intervals. Variables are normalized to equal 1 at their grand means. The dots represent the mean characteristics bundle at each point in time and the arrows represent the overall rate of innovation, measured radially from the origin. 
Figure VI. Historical SimUlations OF ENERGy EFFICIENCY: ROOM Air CONDITIONERS

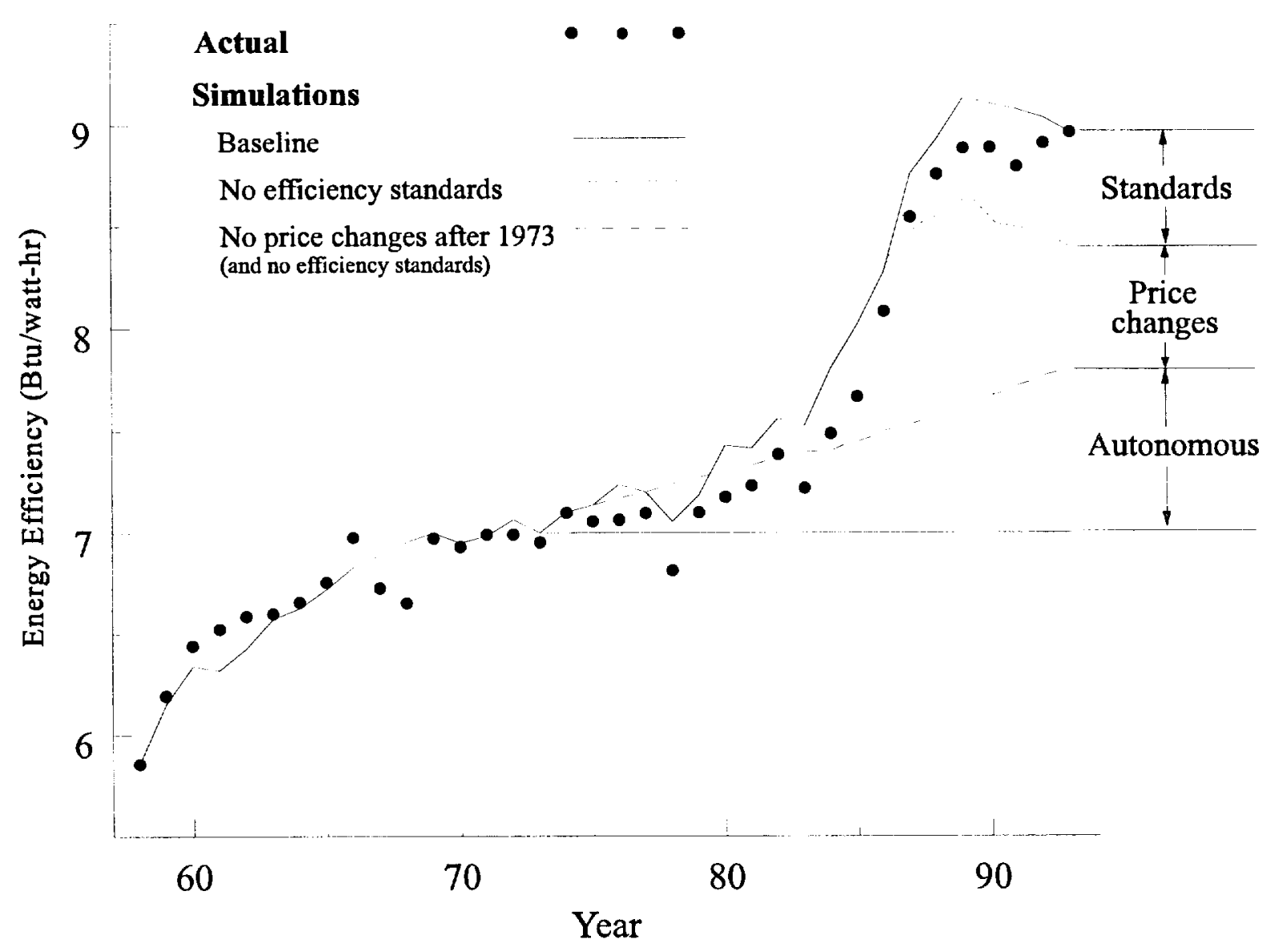




\section{REFERENCES}

Berry, Steven, James Levinsohn, and Ariel Pakes. 1995. Automobile prices in market equilibrium. Econometrica 63(4):841-890.

Energy Information Administration, U.S. Department of Energy. 1980. National Interim Energy Consumption Survey (NEICS). Washington, D.C.

Energy Information Administration, U.S. Department of Energy. 1996. Annual Energy Review 1995. Washington, D.C.

Epple, Dennis. 1987. Hedonic prices and implicit markets: Estimating demand and supply functions for differentiated products. Journal of Political Economy 95(11):59-80.

Gordon, Robert J. 1990. The Measurement of Durable Goods Prices. Chicago: University of Chicago Press.

Hicks, John R. 1932. The Theory of Wages. London: MacMillan.

Jaffe, Adam B. and Robert N. Stavins. 1995. Dynamic incentives of environmental regulations: The effects of alternative policy instruments on technology diffusion. Journal of Environmental Economics and Management 29:S43-S63.

Levin, Richard C., Alvin K. Klevorick, Richard R. Nelson, Sidney G. Winter. 1987. Appropriating the returns from industrial research and development. Brookings Papers on Economic Activity 3:783-820.

Newell, Richard G. 1997. Environmental Policy and Technological Change: The Effects of Economic Incentives and Direct Regulation on Energy-Saving Innovation. Ph.D. thesis, Harvard University, Cambridge, MA.

Office of Technology Assessment, U.S. Congress. 1992. Building Energy Efficiency. Washington, D.C.

Rosen, Sherwin. 1974. Hedonic prices and implicit markets: Product differentiation in pure competition. Journal of Political Economy 82:34-55.

Schumpeter, Joseph A. 1939. Business Cycles, vols I and II. New York: McGraw-Hill.

Sears, Roebuck and Co. 1958-1993. Spring/summer and annual catalogues. Chicago: Sears, Roebuck and Co. 
Stavins, Joanna. 1995. Model entry and exit in a differentiated-product industry: The personal computer market. Review of Economics and Statistics 77:571-584.

Theil, Henri. Economic Forecasts and Policy. Amsterdam: North-Holland Publishing Co.

Thirtle, Colin G. and Vernon W. Ruttan. 1987. The role of demand and supply in the generation and diffusion of technical change. Fundamentals of Pure and Applied Economics, vol. 21. New York: Harwood Academic Publishers.

Trajtenberg, Manuel. 1990. Economic Analysis of Product Innovation. Cambridge: Harvard University Press.

Triplett, Jack E. 1985. Measuring technical change with characteristic-space techniques. Technological Forecasting and Social Change 27:283-307.

Triplett, Jack E. 1987. Hedonic functions and hedonic indexes. In The New Palgrave: A Dictionary of Economics, vol. 2, pp. 630-634, John Eatwell, Murray Milgate, and Peter Newman, eds. New York: Macmillan Press.

United States Code of Federal Regulations. 1995a. 16 C.F.R., Chapter 1, Federal Trade Commission, Part 305-Appliance Labeling Rule. Washington, D.C.

United States Code of Federal Regulations. 1995b. 10 C.F.R., Chapter 11, Department of Energy, Part 430, Subpart C-Energy Conservation Standards. Washington, D.C.

U.S. Department of Energy. 1993. Technical Support Document: Energy Efficiency Standards for Consumer Products, Volumes I-III. Washington, D.C.

White, H. 1980. A heteroskedasticity-consistent covariance matrix estimator and a direct test for heteroskedasticity. Econometrica 48:817-830. 
APPENDIX

FACTORS AFFECTING ENERGY-EFFICIENCY INNOVATION

(Full distributed lag)

\begin{tabular}{|c|c|c|c|c|c|}
\hline Parameter & Variable & Description & Room a.c. & Central a.c. & Gas water heaters \\
\hline \multicolumn{6}{|c|}{ Pre-labeling } \\
\hline$\eta_{00}$ & $\frac{1}{1-\beta} l_{0} \Delta \ln p_{t}$ & $\begin{array}{l}\% \text { change in relative } \\
\text { price of energy }\end{array}$ & $\begin{array}{l}-0.271 \\
(0.194)\end{array}$ & $\begin{array}{c}0.670 \\
(0.270)\end{array}$ & $\begin{array}{l}-0.093 \\
(0.517)\end{array}$ \\
\hline$\eta_{01}$ & & 1-year lag & $\begin{array}{c}0.127 \\
(0.189)\end{array}$ & $\begin{array}{c}0.724 \\
(0.341)\end{array}$ & $\begin{array}{l}-0.154 \\
(0.465)\end{array}$ \\
\hline$\eta_{02}$ & & 2-year lag & $\begin{array}{c}0.309 \\
(0.236)\end{array}$ & - & $\begin{array}{l}-0.288 \\
(0.485)\end{array}$ \\
\hline$\eta_{03}$ & & 3-year lag & $\begin{array}{l}-0.573 \\
(0.323)\end{array}$ & - & $\begin{array}{c}0.693 \\
(0.361)\end{array}$ \\
\hline$\eta_{04}$ & & 4-year lag & $\begin{array}{l}-0.116 \\
(0.215)\end{array}$ & - & - \\
\hline$\eta_{05}$ & & 5-year lag & $\begin{array}{c}0.526 \\
(0.268)\end{array}$ & - & - \\
\hline$\eta_{0}$ & & $\begin{array}{c}\text { Total pre-labeling } \\
\text { price effect }\end{array}$ & $\begin{array}{c}0.001 \\
(0.630)\end{array}$ & $\begin{array}{c}1.394 \\
(0.423)\end{array}$ & $\begin{array}{c}0.158 \\
(0.742)\end{array}$ \\
\hline \multicolumn{6}{|c|}{ Post-labeling } \\
\hline$\eta_{10}$ & \multirow{6}{*}{$\frac{1}{1-\beta_{1 t}} l_{1} \Delta \ln p_{t}$} & $\begin{array}{l}\% \text { change in relative } \\
\text { price of energy }\end{array}$ & $\begin{array}{c}-0.062 \\
(0.191)\end{array}$ & - & $\begin{array}{c}0.369 \\
(0.183)\end{array}$ \\
\hline$\eta_{11}$ & & 1-year lag & $\begin{array}{c}0.098 \\
(0.194)\end{array}$ & - & $\begin{array}{l}-0.120 \\
(0.236)\end{array}$ \\
\hline$\eta_{12}$ & & 2-year lag & $\begin{array}{c}0.235 \\
(0.314)\end{array}$ & - & $\begin{array}{c}0.160 \\
(0.231)\end{array}$ \\
\hline$\eta_{13}$ & & 3-year lag & $\begin{array}{c}0.743 \\
(0.277)\end{array}$ & - & $\begin{array}{c}0.249 \\
(0.210)\end{array}$ \\
\hline$\eta_{14}$ & & 4-year lag & $\begin{array}{l}-0.429 \\
(0.224)\end{array}$ & - & - \\
\hline$\eta_{15}$ & & 5-year lag & $\begin{array}{c}0.590 \\
(0.194)\end{array}$ & - & - \\
\hline$\eta_{1}$ & & $\begin{array}{c}\text { Total post-labeling } \\
\text { price effect }\end{array}$ & $\begin{array}{c}1.175 \\
(0.391)\end{array}$ & - & $\begin{array}{c}0.658 \\
(0.325)\end{array}$ \\
\hline$\theta$ & $\Delta s$ & standards & $\begin{array}{c}0.024 \\
(0.025)\end{array}$ & - & $\begin{array}{c}0.018 \\
(0.008)\end{array}$ \\
\hline$\mu$ & $R$ & $\begin{array}{l}\text { rate of } \\
\text { innovation }\end{array}$ & $\begin{array}{c}0.055 \\
(0.417)\end{array}$ & $\begin{array}{c}0.844 \\
(0.882)\end{array}$ & $\begin{array}{l}-2.835 \\
(3.454)\end{array}$ \\
\hline$\xi$ & $D_{t}$ & direction of innovation & $\begin{array}{l}-0.053 \\
(0.145)\end{array}$ & $\begin{array}{c}0.047 \\
(0.059)\end{array}$ & $\begin{array}{c}0.728 \\
(0.982)\end{array}$ \\
\hline \multirow[t]{3}{*}{$\sigma$} & constant & & $\begin{array}{c}0.007 \\
(0.007)\end{array}$ & $\begin{array}{c}0.001 \\
(0.026)\end{array}$ & $\begin{array}{c}0.009 \\
(0.010)\end{array}$ \\
\hline & & \# observations & 35 & 21 & 31 \\
\hline & $1-U$ & goodness of fit & 0.67 & 0.66 & 0.61 \\
\hline
\end{tabular}

Note: Dependent variable is the rate of change of mean energy efficiency $(\Delta \ln e)$. Estimation method is ordinary least squares. Robust standard errors are reported in parentheses. 